\title{
Reverse Privatization as a Reaction to the Competitive Environment: Evidence from Solid Waste Collection in Germany
}

\author{
Juri Demuth ${ }^{1} \cdot$ Hans W. Friederiszick ${ }^{1,2}\left([) \cdot\right.$ Steffen Reinhold ${ }^{3}$
}

Accepted: 1 October 2021 / Published online: 27 October 2021

(c) The Author(s) 2021

\begin{abstract}
After earlier waves of privatization, local governments have increasingly taken back control of local service provisions in some sectors and countries and instead started providing those services themselves (reverse privatization). Using a unique panel dataset on the mode of service provision for solid waste collection for German municipalities that cover the years 2003, 2009, and 2015, we investigate the motives for reverse privatization. Our results show that-in deciding whether to insource or not-municipalities react to the cost advantages of private suppliers as well as to the competitive environment and municipal activity: there is more switching to insourcing in concentrated markets and in markets with horizontally or vertically related public services. Local interest groups influence this decision as well.
\end{abstract}

Keywords Reverse privatization · Solid waste collection $\cdot$ Mixed oligopoly $\cdot$ Stateowned enterprises $\cdot$ Competition law enforcement $\cdot$ Logit regression

\begin{abstract}
This paper is based on a dataset that was collected in the context of an earlier study that was commissioned by Remondis, a private company that is active in recycling, service, and water distribution (including solid waste collection). The opinions that are expressed in this paper are the authors' and should not be attributed to Remondis. The same is true for all errors and mistakes in this paper.
\end{abstract}

$\triangle$ Hans W. Friederiszick

friederiszick@e-ca.com

1 E.CA Economics, Berlin, Germany

2 ESMT Berlin, Berlin, Germany

3 Frontier Economics, Berlin, Germany 


\section{Introduction}

There is a continuing discussion about the relative merits of public versus private provision of services and the potential competitive distortions that arise from the role of public providers. This discussion has heated up again, as in recent years municipalities across the globe have taken back control of service provision from the private sector in the areas of energy, water, and waste collection, and have started providing these services themselves. The process toward insourcing ("reverse privatization") ${ }^{1}$ has reversed earlier waves of privatization during the 1980 s.

In this paper, we use the example of solid waste collection service to show that this trend also exists in Germany. More importantly, we analyze municipalities' motives for reverse privatization; we focus on motives that are related to the competitive interaction of private and public providers.

Our analysis relies on a panel dataset that provides the status (in-house versus private provision) for all of the German municipalities (more than 11,000) for the years 2003, 2009, and 2015. ${ }^{2}$ Bel and Fageda (2007, pp. 528-529) point out that only studies that are based on changes in the status, instead of levels, allow a proper analysis of the motivations for (reverse) privatization. ${ }^{3}$

Accordingly, we built an indicator variable of changes in status between observable time periods. This allows us to analyze two episodes of switching: Episode 1 reflects the changes in status between 2003 and 2009; episode 2 reflects the changes in the time period between 2009 and 2015. The year of the switchover is known for a subsample of the dataset (albeit with some measurement error), which allows us to analyze annual data as well.

Given economies of scale across municipal borders-cost advantages for a provider that is active in neighboring municipalities-markets are local. Exploring cross-market variation, we estimate the probability that a municipality reverts to privatization as a function of: (i) local concentration (measured by the CR3 of private service providers in local markets); (ii) local experience in in-house provision (measured by the share of in-house provision for neighboring municipalities); (iii) vertically related local public service (measured by the proximity of state-owned incinerators); and (iv) the existence of local incumbents (measured by the residents that are served locally by a company relative to its nationwide coverage).

We find a statistically significant effect on reverse privatization in at least one of the episodes for all four factors. The results are also economically significant. We show that variations in those four factors are capable of moving predicted probabilities of switching by considerable amounts compared to the baseline probability.

\footnotetext{
1 This notion was introduced by Warner and Hebdon (2001) to characterize the complex process of providing government services by local governments in New York State, which involved both contracting out and contracting in.

2 Very small municipalities - which represent less than $1.2 \%$ of the entire population-are dropped from the econometric analysis. See Sect. 4.1 for a discussion.

3 The authors hypothesize that this is due to inertia of the decision process of municipalities with regard to the mode of provision of public services. This concern is also shared by Mohr et al., (2010, p. 901) and in Bel and Fageda (2017, p. 504).
} 
If those factors are changed from their median values to their $99 \%$ percentile, the switching probability increases substantially: In the first episode it increases from 12.1 to $36.5 \%$, and in the second episode from 4.6 to $14.9 \%$. The estimated coefficients for additional explanatory variables are in line with the results from earlier studies.

In Sect. 2, we describe the institutional background of the service industry for solid waste collection in Germany. In Sect. 3 we summarize the related literature. Section 4 introduces the data, the variables that we use, and the descriptive statistics. Section 5 delivers our empirical assessment, and Sect. 6 offers policy conclusions.

\section{Institutional Background}

Municipalities in Germany have a legal monopoly on service provision in the solid waste collection industry. In this context, a municipality can decide whether to rely on in-house provision (-through its own internal units or through inter-municipal cooperation-or to contract out in competitive bidding: to a private supplier, a municipal enterprise that participates in a competitive tender, or to a private-public partnership entity.Households have to use the waste collection service that is chosen by the municipality. ${ }^{4}$

Some municipalities - especially in rural areas - are quite small and would not be large enough on their own to support a provider that operates only there. Since municipal providers do not often venture into neighboring municipalities, ${ }^{5}$ private providers have cost advantages in those areas.

However, there are also possibilities for municipal providers to capture economies of scale across municipalities: First, small municipalities can be merged. In this case, the predecessors disappear as legal entities, and a new municipality results, which holds all rights and duties of its predecessor. Indeed, in recent years there has been an ongoing trend for municipal consolidation. In our empirical assessment, however, we had to drop these municipalities, as it is not feasible robustly to link the predecessor and successor municipalities over time. By dropping these data, we can also rule out that the trend towards reverse privatization is driven by merger activity.

Second, municipalities can form a municipality association ("Gemeindeverband"). When doing so, the individual municipalities are permanently incorporated into a larger legal entity. The municipalities transfer responsibilities to the higher level: not only waste collection but also other services. In contrast to a fully merged municipality, however, they keep separate names and, hence, represent separate

\footnotetext{
4 See "Gesetz zur Förderung der Kreislaufwirtschaft und Sicherung der umweltverträglichen Bewirtschaftung von Abfällen”. (KrWG), sections 17 (1) and 20 (1). In contrast, commercial customers-while being required to dispose of their waste-are not required to use a particular provider. Our study focuses on the service provider for households.

5 Depending on state law, a municipal provider may also offer services to neighboring municipalities by participating in the tendering process. However, many states prevent municipalities from offering economic services in neighboring municipalities in a competitive process (Monopolies Commission, 2013, Table V.1).
} 
observations in our dataset. They also keep some of their responsibilities. We control for this type of collaboration in our empirical analysis. We observe that with waste collection, there is often-but not always - uniformity in the mode of service within the association.

Finally, municipalities can form an inter-municipal cooperative: "Zweckverband". This cooperative focuses on narrowly defined specific areas of cooperation: which potentially includes waste collection or the operation of an incinerator. By forming an inter-municipal cooperation, the municipalities maintain independent decisionmaking in providing other services. If waste collection is included in the shared responsibilities, an inter-municipal cooperative can contract out the specific service or provide the service itself for the entire group of municipalities. Inter-municipal cooperatives with a focus on waste collection cannot be identified in the dataset. Therefore, we cannot explicitly investigate the impact of inter-municipal cooperation but consider it one mechanism as to how the contagion effects to neighboring municipalities work. ${ }^{6}$

Municipalities hold a dual role as regulator and potential supplier. In addition, municipalities often are active suppliers in vertically related markets. In this paper, we focus on the role of publicly owned waste incinerator plants. In 2005, disposing of untreated household waste (containing organic components) in landfills was outlawed. Landfills are now used only for inorganic waste-mostly from construction - and for the slag from waste incineration.

In 2005, it was anticipated that there would be heightened demand for waste incineration as the next cheapest alternative to landfills. Therefore, many municipalities_ — often forming inter-municipal cooperatives for this purpose-decided to build new plants. However, because of the introduction of the so-called dual-system and separate waste collection schemes for packaging materials, the amount of household waste decreased by 30\% between 1996 and 2011 (Monopolies Commission, 2014, recital 1298), which led to excess capacity in waste incineration. Because of the high fixed costs of running a waste incineration plant, this has given municipalities an incentive to steer volumes to their plants (Monopolies Commission, 2014, recital 1298). ${ }^{7}$

\section{Related Literature}

Reverse privatization has been observed mostly in the US and Canada (Hefetz \& Warner, 2004, 2007; Bel \& Fageda, 2007, FN18, Warner \& Hefetz, 2012; Warner $\&$ Aldag, 2021). However, more recently this phenomenon has been documented

\footnotetext{
${ }^{6}$ Recently, inter-municipal cooperation has been studied in Germany in the context of waste water management (Blaeschke and Haug, 2018) and local tourism (Bergholz, 2018). Bergholz and Bischoff (2018) have investigated local council members' views on this form of cooperation. From the latter study emerges that loss of political power is a barrier for inter-municipal cooperation, especially when small municipalities cooperate with larger municipalities.

${ }^{7}$ Steering volumes to public incinerators may be more easily achieved when municipalities provide waste collection in-house, thereby offering one motive for reverse privatization. See Sect. 4.3 below for a comprehensive discussion of how a municipality's ownership of an incinerator can influence its incentives for reverse privatization.
} 
also in the UK, the Netherlands, New Zealand (Gradus \& Budding, 2020; Gradus et al., 2014), Spain (Campos-Alba et al., 2021), and in the water sector in France and in Germany (Hall et al., 2013). The German competition authority (2014, p. 17/18) identifies a tendency toward reverse privatization from mid-2000 onwards: specifically in the energy sector but also in waste collection, water markets, and the broadband sector.

Three categories of factors that influence the choice of mode of service provision are distinguished in the literature: economic efficiency, fiscal constraints, and political processes and ideological attitudes (Bel \& Fageda, 2007, 2009, 2017). In addition, some studies also investigate the role of services' characteristics on the choice of service provision for a broad range of services (for instance Campos-Alba et al., 2021; Levin \& Tadelis, 2010). Levin and Tadelis (2010) show that city managers see solid waste collection's characteristics generally as favorable for private provision. Residents' sensitivity to quality problems is, in comparison to other types of public services, the only limiting factor.

One important rationale for privatization, which is related to economic efficiency, is exploiting economies of scale across municipal borders (Donahue, 1989). Private firms find it easier to operate across municipal borders, which allows them to provide the services at lower per-unit costs. In general, the literature has found that economies of scale (measured by municipality size) are an important factor in explaining privatization decisions (Bel \& Fageda, 2009). More recently, Böckers et al. (2017) have found public provision to be more likely in larger and more densely populated areas in Germany. ${ }^{8}$

The role of local competition has been analyzed in only a few recent studies (Bel \& Fageda, 2017). Warner and Hefetz (2012, p. 321) analyze reverse privatization for US services during the period 2002 to 2007. In their regression model, measures of market concentration are not statistically significant. However, dual sourcing-parallel public and private provision-has the expected impact on reverse privatization, which indicates that dual sourcing works as a competitive threat.

In an earlier study for the US, Hefetz and Warner (2004) have found that there is more reverse privatization and less privatization when there is an insufficient number of suppliers. Similarly, public managers are more likely to contract out when they perceive an insufficient number of competent suppliers in central and suburban areas where the availability of suppliers should be greater (Fernandez et al., 2008). In the US, it also has been found that smaller municipalities are less likely to use a competitive bidding process in the first place, which potentially explains why they are also less likely to realize cost savings from privatization (Mohr et al., 2010).

With more competition, privatization can become more attractive for municipalities that anticipate a better price for the services. In fact, two studies for the Netherlands-Gradus et al. (2016) and Gradus et al. (2018)-have found that higher

\footnotetext{
${ }^{8}$ Böckers et al. (2017) provide information for one year of whether the waste collection service is provided by a private or public operator for all German municipalities. A switching analysis is not (and cannot) be carried out on their dataset.
} 
concentration increases costs for private provision, since municipalities cannot expect to receive competitive bids with fewer suppliers.

Bel and Fageda (2017) also note that there are spill-over effects, and privatization becomes more likely when other nearby municipalities also have privatized services (see Alonso et al., 2016 for evidence for the UK). From this literature, different reasons for potential spill-overs emerge: Local governments might be evaluated by their electorate or higher-level government agencies by benchmarking their practices against the performance of similar municipalities; by adopting the same practices as neighboring municipalities, local decision makers can shield themselves against bad evaluations. Furthermore, there might be learning and information exchange between municipal decision-makers, which leads to a diffusion of some practices. Municipalities might also engage in formal or informal inter-municipal cooperation, which leads them to adopt similar practices as their neighbors.

Another strand of literature has addressed specifically the role of inter-municipal cooperation (Bel \& Gradus, 2018)—especially among smaller municipalities. Smaller municipalities appear to be less likely to reap the potential benefits of privatization: because there are fewer potential suppliers, and also because they are less well equipped to organize competitive bidding (Hefetz \& Warner, 2007). When faced with these difficulties, municipalities may rely more strongly on inter-municipal cooperation, either to provide services jointly in-house or to be better able to organize competitive bidding. For instance, Bel and Fageda (2008) document that inter-municipal cooperation is sometimes used as an alternative to local privatization, with privatization being negatively related to inter-municipal cooperation.

\section{Data and Descriptive Statistics}

For the analysis, we rely on two main data sources: (i) a dataset that provides information on the mode of service provision in each municipality (the "municipality dataset"); and (ii) public statistics on various aspects of the municipalities' characteristics. In the following, we describe the underlying data.

\subsection{Mode of Service Provision}

The municipality dataset ${ }^{9}$ covers more than 11,000 German municipalities for the years 2003, 2009, and 2015. Thus, in principle, the dataset contains information on all German municipalities, and it is possible to take repeated measurements on an individual municipality over time. However, the number of municipalities declined over the observation period from 13,358 in 2003 to 11,253 in 2015 because of administrative mergers (or more complex redefinitions of borders) between

\footnotetext{
9 This data was collected by Remondis: a German company for recycling, water resource management and industrial and communal services. Remondis is one of the largest private suppliers for solid waste collection from households in Germany. The dataset is based on publicly available information and the business knowledge of Remondis.
} 
municipalities, which sometimes resulted in difficulties to identify a municipality over time. Those municipalities were dropped.

Furthermore, the original dataset includes municipalities with very few inhabitants (the lowest number is 4) and a very small area (the minimum is $0.4 \mathrm{sq} \mathrm{km}$ ). Those smaller municipalities are often members of a municipal association.

As it is implausible to assume that those very small municipalities take independent decisions on how to organize waste collection in their area, we excluded them from our econometric analysis. Small municipalities are defined as having no more than 500 residents at the beginning of the relevant episode. The excluded municipalities represent less than $1.2 \%$ of the entire population. ${ }^{10}$

The municipality dataset consists of information on the supplier that holds a solid waste collection contract with a municipality or whether the municipality provides this service in-house. It is considered in-house provision when the service is provided by the municipality itself or through cooperation with another municipality, as a competitive tender is not required.

Service provision by a private supplier, by a municipal enterprise that participates in a competitive tender, and by a private-public partnership is considered "external provision". ${ }^{11}$ Based on this information, we create a dummy variable that takes the value 1 if the municipality provides services in-house, 0 otherwise.

Based on changes of this dummy variable over time, episodes of (reverse) privatization can be identified. The year of reverse privatization is known for only a subset of observations and is imperfectly measured even for this subset. Thus, for our main analysis, we define a reverse privatization event when, for the first episode, the service in 2003 is not provided in-house but in 2009 it is. For the second episode, a reverse privatization event is found when the service in 2009 is not provided inhouse but in 2015 it is.

The following transition table provides an overview of the share of municipalities, which did or did not switch between in-house and no in-house provision for the two episodes: 2003 to 2009; and 2009 to 2015.

As can be seen in Table 1, between 2003 and 2009 8.6\% of all municipalities reversed privatization: There was no in-house provision in 2003, but there was

\footnotetext{
${ }^{10}$ We provide a sensitivity analysis that excludes municipalities with 250 or fewer residents. The results become slightly less significant but are qualitatively the same.

11 This definition centers on the requirement of a competitive tender. Given the focus of this paperthe effect of local competition-this seems to us to be the most relevant delineation. If one seeks an answer to the question of the role of state institutions in the economy, private-public partnerships and commercial offers by public firms also potentially qualify as the public provision of commercial services. Note that a private public partnership does not need to participate in a competitive tender in the first row (when founded) but only for extension of its contract. Hence, it also makes sense here to consider a private-public partnership to be "private provision" of the services, as reverse privatization of a privatepublic partnership will occur in light of the requirement to tender the contract competitively otherwise. In our econometric analysis, we also tested a specification where we dropped the switching events that are related to private-public partnerships, and the results are not substantially affected thereby.
} 
in-house provision in 2009. As can be seen in the gray cells (and taking the sums), switching occurred more often $(9.9 \%)$ during the first episode than during the second (4.8\%). Across both episodes, switching occurred predominantly from "no inhouse provision" to "in-house provision": reverse privatization.

Switching from "in-house provision" to "no in-house provision"-privatization-is a rare event and occurs mostly in the first episode. In absolute terms, we observe 126 privatization events between 2003 and 2009, and five between 2009 and 2015. ${ }^{12}$ The low number of privatization events prevents a robust analysis these events. This compares to 823 and 425 reverse privatization events in the first and second episodes, respectively.

As a consequence of this trend towards reverse privatization, 25 percent of all municipalities were using in-house services for waste collection in 2015, while in 2003 only 14 percent were relying on in-house services. ${ }^{13}$

\subsection{Economic Efficiency}

The German Federal Statistical Agency, Destatis, provides information on the population, population density, area, and geo-coordinates for each municipality. We use the population and area as relevant measures. Population and area are relevant variables to control for efficiency differences in public versus private service provision (Bel \& Fageda, 2009).

As discussed above, smaller municipalities often form municipality associations and transfer some responsibilities to this higher level. We measure population and area at the level of the associations for these smaller municipalities. In a robustness check, we also show results that rely on the population and area measured at the individual municipality level. We also control for the membership in a municipal association and whether the municipality is an independent town.

\subsection{Indicators of Local Competition and Nearby Public Activity}

Based on geo-coordinates and population data, we construct variables that summarize the competitive environment in the solid waste collection industry: In line with the practice of the German Competition Authority ${ }^{14}$ for each company, or the group to which it belongs, we calculate market shares: the share of residents who are served among the municipalities that rely on external provision ${ }^{15}$ in a $100-\mathrm{km}$ circle

\footnotetext{
12 Absolute numbers of switching events are given in "Appendix 1".

13 Please note that this statistic is conservative with respect to the involvement of public entities in municipal enterprises that participate in a competitive tender and private-public-partnerships are considered "no in-house provision" for the purpose of this analysis.

14 See, for instance, Sulo and Cleanaway (2006), Remondis/RWE Umwelt (2005), Rethmann / Entsorgungs-Service Anhalt-Mitte GmbH / Tönsmeier (2004).

15 See the definition of "external provision" in Sect. 4.1.
} 
Table 1 Switching events in percent

No in-house provision in 2009

In-house provision in 2009

\begin{tabular}{lll}
\hline $\begin{array}{l}\text { Switching between 2003/2009 } \\
\text { No in-house provision in 2003 }\end{array}$ & $78.1 \%$ & \\
In-house provision in 2003 & $1.3 \%$ privatization & $8.6 \%$ reverse privatization \\
\hline & No in-house provision in 2015 & In-house provision in 2015 \\
\hline Switching between 2009/2015 & & \\
No in-house provision in 2009 & $75.4 \%$ & $4.7 \%$ reverse privatization \\
In-house provision in 2009 & $0.1 \%$ privatization & $19.9 \%$ \\
\hline
\end{tabular}

Source: The authors, based on the municipality dataset. Excludes municipalities with 500 or fewer inhabitants

around the midpoint of each municipality — not considering the county in which the municipality is located. ${ }^{16}$

During previous merger cases, the Authority has undertaken analyses of bidding data and found that there are only a few bids from companies without active contracts within a $100 \mathrm{~km}$ radius around the target municipality. The concentration ratios of the three largest providers (CR3) are calculated based on these market shares. ${ }^{17}$ We provide sensitivities with $50 \mathrm{~km}$ and $25 \mathrm{~km}$ radii and the HHI index as an alternative measure of concentration. ${ }^{18}$

To measure the regional effects of close-by public activity in waste collection, we calculate the share of municipal provision of this service: the share of residents who are served, in the neighborhood, based on a $25 \mathrm{~km}$ circle around the target municipality. For this calculation, we exclude the target municipality. We restrict the radius to $25 \mathrm{~km}$ because the flow of informal information between municipal decisionmakers is more likely in those neighboring municipalities than in a broader radius. Again, we provide a sensitivity check where we calculated the share of municipal provision within a radius of $100 \mathrm{~km} .{ }^{19}$

In order to measure public activities at other stages of the vertical value chain, we analyze ownership of waste incinerator plants nearby to the target municipality. The

\footnotetext{
16 The rationale for this exclusion will be provided below.

17 We also provide a sensitivity with CR(3) that is based on market shares that are calculated as the number of municipalities that are served by a company divided by the number of municipalities provided by any private supplier-market shares that are not population-weightedin the last column of Table 11 .

18 Gradus et al. (2016) and Gradus et al. (2018) apply a radius of 30, 50, and $70 \mathrm{~km}$ for the Dutch waste collection market. They also discuss alternative concentration measures but do not find substantial differences between those measures.

19 This sensitivity check, which is provided in Table 11, indicates that-if calculated within the same radius of $100 \mathrm{~km}$ - the municipal share also captures to some extent local market concentration and thereby lessens the measured effect for the direct concentration measure. This is driven by the fact thatwhen calculated at a radius of $100 \mathrm{~km}$ - the municipal share is often above $60 \%$. As the CR3 is calculated from the remaining market that is served by private companies, this becomes too small to serve several private firms and the CR3 increases as well. Hence, the two effects cannot be separated.
} 
hypothesis here is that a municipality that holds ownership of an incinerator has an incentive to reverse-privatize its waste collection.

Principally, the decision as to which incinerator, public or private, to use rests with the municipality-independently of whether waste collection is done by an external provider or in-house. Why may the ownership of an incinerator induce inhouse provision of waste collection? We consider the following chains of effects plausible:

Public incinerators are often organized as inter-municipal cooperation projects, where many municipalities have common ownership of the waste incinerator. This is the case because incinerators are expensive and their capacity is sufficient to serve several municipalities.

Common ownership drives the incentives to feed this incinerator-specifically in a phase of severe overcapacity, as was the case during the relevant period. While this is feasible for a municipality independent on how it organizes the collection of waste, it is more easily done-and potentially more efficiently done-if the waste collection is provided in-house. For instance, the quantities collected are less visible for private market participants (some of the private waste colleting firms do also own incinerators) and can be allocated to the integrated incinerator without public tender. Also, if collection, sorting, and thermal utilization are all done by one operator, efficiencies may arise: A vertically integrated operator may reduce its sorting effort if there is an underutilization of the incinerator.

Furthermore, cross-subsidization may allow the "hiding" of losses that occur via an underutilized incinerator: E.g., a municipality can consolidate the losses that it incurs from the incinerator with the profits that it makes via in-house waste-collection. This will allow the municipality to hide a politically sensitive loss-making investment; it also allows - under specific circumstances - a saving of federal taxes. Again, those municipalities that hold common ownership of an incinerator have a greater incentive towards reverse privatization.

Finally, common ownership of an incinerator may result in an extension to other, related economic activities. Based on the proven capabilities to run an inter-municipal cooperative incinerator jointly, the same municipalities may consider extending the purpose or forming an additional inter-municipal cooperative for waste collection.

Empirically, the information as to whether an incinerator is owned by a private or public company can be collected from public sources. However, given complex ownership structures it was not feasible for us to identify properly whether a specific target municipality holds common ownership of a specific incinerator or not. Instead we relied on a measure of proximity. Given the importance of transport costs, the distance to a publicly owned incinerator is an indicator of (common) ownership in this incinerator.

Information on the locations of plants comes from the Federal Ministry for the Environment, Nature Conservation, Building and Nuclear Safety and from ITAD (the trade organization of waste incinerator plants). All sites are geocoded with the use of Google Maps. We also collect information on whether the incinerator plant is 
in municipal hands or privately held, as of today. Entry and exit, and change in ownership is considered as far as public information is available. ${ }^{20}$

We then calculate the distance to the next municipal waste incinerator plant for each municipality. Based on this distance and the maximal distance observed between a municipality and its next municipal waste incinerator (labeled Max(Distance); it takes a value of $215 \mathrm{~km}$ in our sample), we derive a proximity measure that is based on the following formula:

$$
\text { Proximity }=\frac{\text { Max }(\text { Distance })-\text { Distance }}{\text { Max }(\text { Distance })} * 100
$$

If the incinerator is situated in the center of a municipality, the distance to it is zero, and the proximity measure takes on the value of 100 . If the distance from the center of the municipality to the waste incinerator plant is the maximum observed distance, the proximity measure takes on the value 0 . Thus, the proximity measure is a re-scaled version of distance, taking values between 0 and 100, and can be interpreted as the reverse percentage distance relative to the maximum observed distance.

Finally, we included a measure of the economic importance of a given county for the firm that currently holds the waste collecting contract ("the incumbent"). This measure, labeled "local incumbent", measures the importance of a specific county in the nationwide portfolio of the firm. More specifically, it is measured as the number of residents who are served by the company within the county relative to the number of residents who are served by the company nationwide. This measure is equal to one for a company that serves residents only in the county in which the targeted municipality is located; it becomes very small or even close to zero for a contract holder that is active nationwide. Hence, a company with a local incumbent measure that is close to one economically depends on this region; it may also be more deeply locally rooted.

\subsection{Other Explanatory Factors}

In line with the related literature, we control for fiscal constraints, political processes and ideological attitudes. The indicators that we deploy are described below. Please note that while we collect data for the years 2003, 2009, and 2015, only the values for the years 2003 and 2009 are relevant for our main econometric analysis as we use lagged explanatory variables in the analysis. The 2015 results are used only for the analysis on a subset of data for which we have measures of the exact switchover year.

\footnotetext{
${ }^{20}$ Most of the investment in new incinerator capacity was induced by the phasing out of landfills in 2005. After this date, unsorted waste from households could no longer be brought to landfills, but instead had to be treated differently. Accordingly, during the period 2004 to 2009 significant additional incinerator capacity was brought into the market. See Energie Brainpool (2017, p. 21).
} 


\subsubsection{Fiscal Constraints}

We use the per-capita tax revenue for the years 2003, 2009, and 2015 at the county level to build an inverse measure of the fiscal constraints that a municipality faces. Municipalities with a lower per-capita tax revenue are potentially more constrained; municipalities with a higher per-capita tax revenue are less constrained.

A municipality that has to act under more severe financial constraints may have stronger incentives to privatize unprofitable public services or, alternatively, to insource profitable public services. Furthermore, municipalities with financial constraints might have an additional incentive to reverse privatize if an in-house provider allows cross-subsidization of less profitable services (such as cleaning public parks). ${ }^{21}$ An alternative measure of fiscal constraints-public debt-was not usable because of a break in methodology in the official statistics.

\subsubsection{Political Processes and Ideological Attitudes}

Three variables are available to measure differences in the political processes and ideological attitudes across municipalities and over time: the unemployment rate; municipal employees as a share of total local employment, as a measure of the political process; and leftist parties' vote shares, as a measure of ideological attitudes.

With regard to the first variable: The unemployment rate is used as a measure of the social and economic pressure on local politicians. A high unemployment rate may trigger a political debate on insourcing economic activity in order to increase local employment. These data are available at the German Statistical Office at the county level for the years 2003, 2009, and 2015.

The second variable - the public employee share of local employment-can also be considered to be a measure of pressure on local politicians from within the administration to keep or even to extend the scope of municipal economic activity. It is calculated as the number of municipal employees in a county relative to total employment in a county. These data are also available at the German Statistical Office at the county level for 2003, 2009, and 2015.

With regard to the third variable: The results from the federal elections at the municipality level taken from the Federal Returning Officer are deployed as a measure of ideological attitudes. The federal elections took place in September 2002, 2009 , and 2013. The election outcome is matched to the municipal dataset for the years 2003, 2009, and 2015, respectively.

From those results, we generate a summary variable: the sum of the leftist parties' vote shares: Social Democrats ("SPD”), Green Party ("Die Grünen"), and the Socialist Party ("Die Linke"). While those results do not give direct information

\footnotetext{
21 The municipalities levy a fee on households for collecting the trash; this is true for in-house municipalities and for municipalities that have contracted out this service. This fee is supposed to reflect the actual costs of collection. Hence, there should be no direct budget implications from that perspective. However, municipalities have some leeway to set the fees, and may use that leeway especially when providing the service in-house as the difference between fees and costs is less transparent to the general public in this case.
} 
about who governs a certain municipality, it does give a general tendency about the political leanings of the citizens in a certain municipality. The expectation is that in municipalities with a higher leftist party share insourcing occurs more frequently.

As an alternative measure to the results of national elections at the municipal level, we also collected election data for municipal elections that are provided by the individual statistical offices of the German states. As decisions about the mode of service provision for solid waste collection are taken on the municipal level, those elections may be considered more relevant to reflect the ideological attitudes that drive local decisions with regard to waste collection. However, this dataset is incomplete and-given the more diffuse political landscape at local elections-categorization of candidates into the political left-right-spectrum is not feasible. Therefore, we consider the vote share of leftist parties based on national elections more reliable.

\subsection{Summary Statistics}

Table 2 summarizes the main variables that we use.

Table 3 provides the descriptive statistics of the explanatory variables. We show the summary statistics both for all municipalities and for those municipalities that do not provide the services in-house. The latter is the basis of our regression results as we restrict the analysis to switch-overs from no in-house provision to in-house provision.

\section{Empirical Assessment}

In the empirical assessment, we investigate switching events to identify the motives for in-house provision using both visual analysis and econometric analysis.

\subsection{Visual Analysis}

Figure 1 offers a regional view of the evolution of reverse privatization. The dark areas represent municipalities that provide solid waste collection in-house. The lighter areas are the regions that are served by private firms, private-public partnerships, or public firms that act commercially. Over time, there is a clear increase in in-house provision. The nation-wide share increases from about 36.1 to $45.6 \%$. $^{22}$

We also depict the location of incinerators in public ownership. This is due to the hypothesis that publicly owned incinerators also trigger the public collection of solid waste: Steering waste to the public incinerator may be more feasible in the case of public waste collection.

Notably, reverse privatization occurs mostly in areas where there has already been municipal provision. This is aligned with the hypothesis of the existence of

\footnotetext{
22 Our findings for the year 2015 are broadly consistent with the market shares that were calculated by Böckers et al. (2017) for the same year.
} 


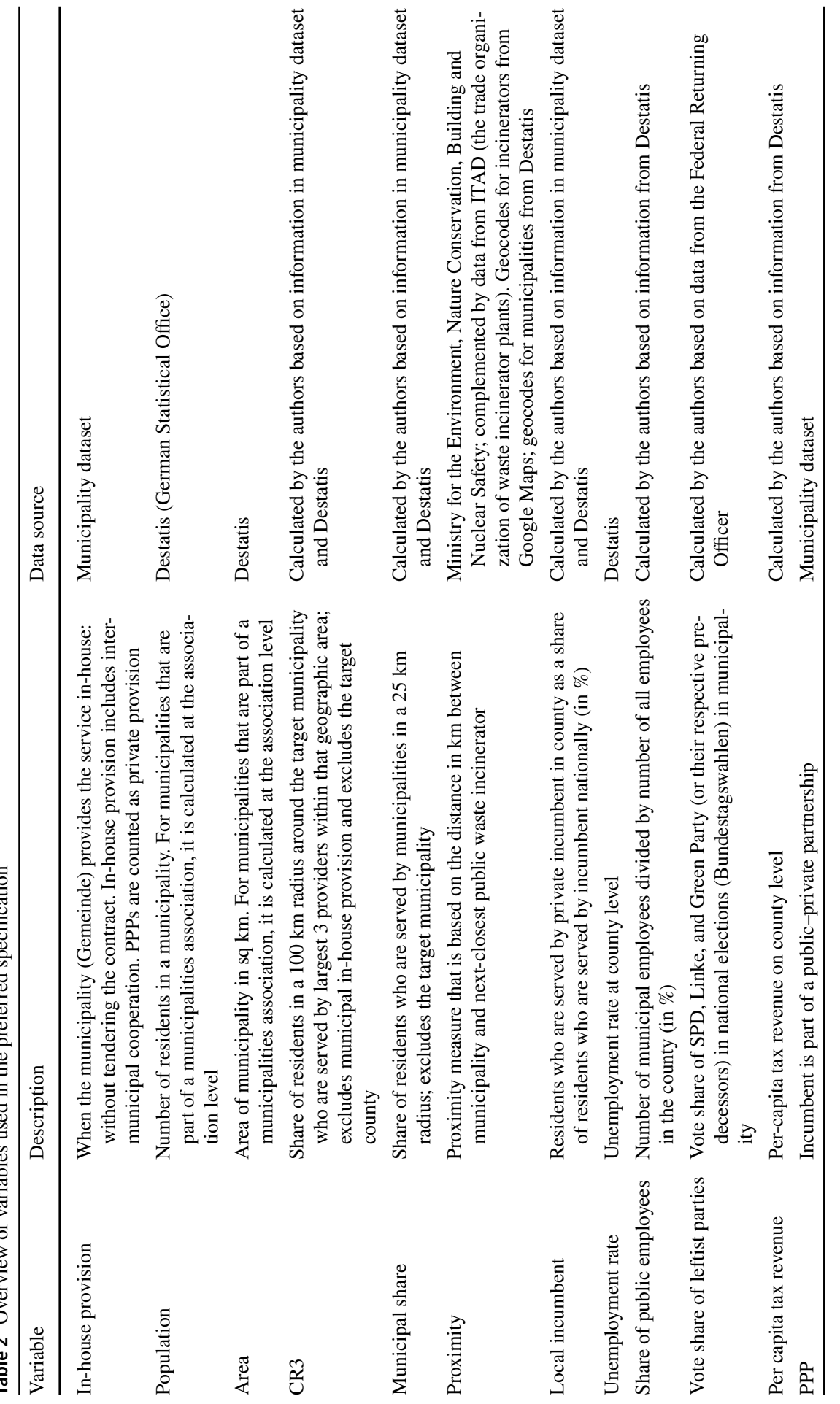




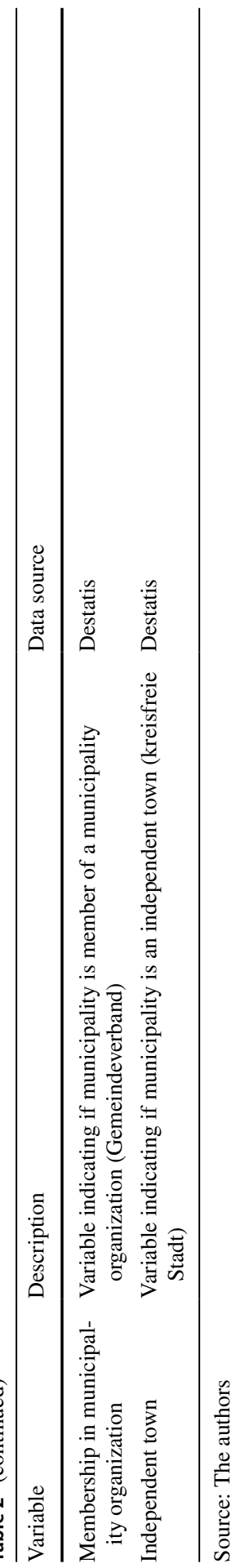




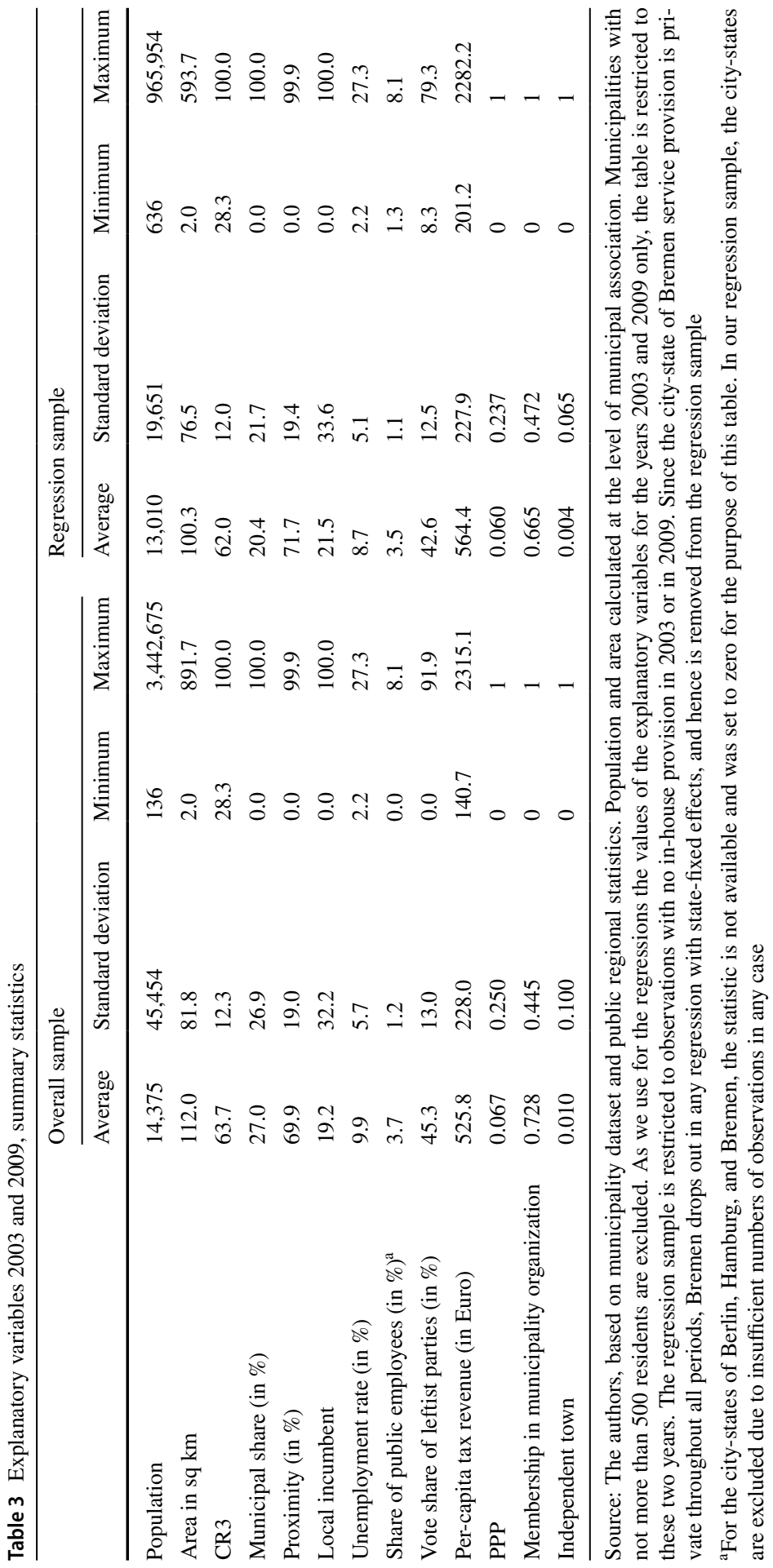




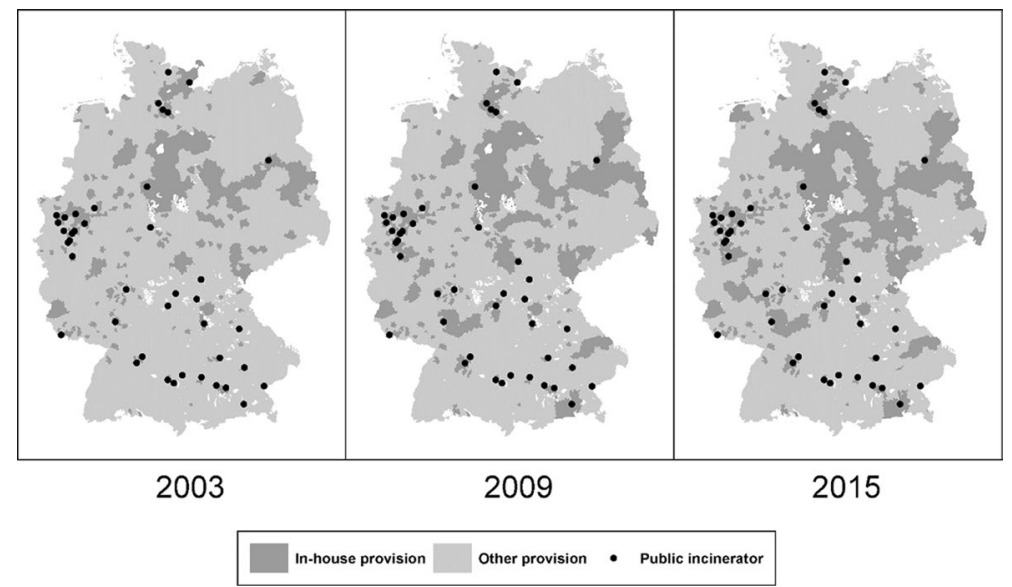

Fig. 1 In-house provision of solid waste collection in Germany, 2003, 2009, and 2015. Source: The authors based on the municipality dataset and publicly available information on public incinerators

local contagion effects. While local clustering is more pronounced in the eastern part of Germany - the Neue Bundesländer - the phenomenon is observable across Germany.

Figure 1 also offers some first indications that the proximity of public incinerators is correlated with regions' being reverse privatized. This is, for instance, the case in the Ruhr Valley (in the West) and the region around Hamburg (in the North). Here, the proximity of a large number of publicly owned incinerators coincides with a large fraction of the markets being served by public waste collection. This coincidence is less obvious in the southern parts of Germany.

Figure 2 shows the development of regional market concentration. As can be seen, concentration increased over time, with the exception of the Ruhr Valley from 2003 to 2009. The most pronounced increase of concentration occurred in the Neue Bundesländer - a region that also experienced a substantial wave of reverse privatization.

\subsection{Regression Analysis}

\subsubsection{Empirical Model}

In the following regression analysis, the switching behavior of municipalities over the period 2003 to 2015 is analyzed within a logit model framework. We focus on switches, since contemporaneous explanatory variables have low explanatory power for the service provision mode-which was often decided many years earlier (Bel \& Fageda, 2007, p. 528 and 2017, p. 504).

In analyzing reverse privatization, the sample for the first episode (2003 to 2009) is restricted to municipalities that in the base-year 2003 do not offer the service inhouse. Equally, for the second episode (2009 to 2015), the sample is restricted to municipalities that do not offer the service in-house in the base-year 2009. 
In other words, municipalities that have reverse-privatized between 2003 and 2009 drop out of the sample for the second episode, whereas municipalities that have privatized between 2003 and 2009 are added as potential candidate for reverse privatization in the second period.

We use a logit model of the following form:

$$
\operatorname{Pr}\left(R P_{i t}=1 \mid x_{i t-6}\right)=\frac{\exp \left(x_{i t-6} \beta\right)}{1+\exp \left(x_{i t-6} \beta\right)},
$$

with $t=\{2009,2015\}$ and $i$ representing individual municipalities. Within that framework, reverse privatization- $R P=\{0,1\}$-during a particular episode is measured at the end of the episode $\mathrm{e}^{23}$ and is explained by the observed variables (represented by the vector $x$ ) at the beginning of the episode.

We deploy lagged explanatory variables to reduce reverse causality problems. For example, in-house provision could have an effect on the economic conditions in a municipality by relying on more employees than private suppliers, thereby reducing unemployment. In this case, a lower contemporaneous unemployment rate will coincide with, but not cause, reverse privatization.

Equally, in-house provision may reduce contemporaneous tax revenues of the municipalities, as local profit taxes do apply to a private provider but not-depending on how the in-house entity is set up-the public entity. Again, lower contemporaneous tax revenue is then correlated with a switch over to public provision of the services. However, such effects can occur only after a reverse privatization has already happened. Deploying lagged explanatory variables reduces these concerns.

In addition to using lagged values for our explanatory variables, endogeneity concerns are also addressed by excluding from the measure of local competitionCR3 - the county to which the municipality belongs. Equally, we exclude from the measure of local experience of in-house provision - the share of in-house provision for neighboring municipalities - the municipality itself.

To account for the potential dependence of decisions within a municipality association, we add a control variable for membership in such an association. For municipalities within an association, population and area are measured at the level of the association. ${ }^{24}$ Furthermore, we include a control variable for larger cities which are an independent county.

Standard errors are clustered at the level of municipality associations, so as to consider the potential interdependence of decision making. We also exclude very small municipalities (500 or fewer residents), since they are unlikely to take

\footnotetext{
${ }^{23}$ Ideally, one would like to identify the exact year of switching for the analysis. This is, however, not available in the dataset. For a subsample of the dataset (about $82 \%$ of the observations) the expected contract end is also provided. As a robustness test we offer an estimation that uses the expected contract end as the switchover date, when there is switching. Our results are confirmed by this analysis. Given the reduced sample size and a potential measurement error for contracts with a prolonged term, we consider the approach that we take in the main body of this paper to be superior.

${ }^{24}$ In a robustness check, we also use a measure of population and area at the individual municipalities' levels.
} 


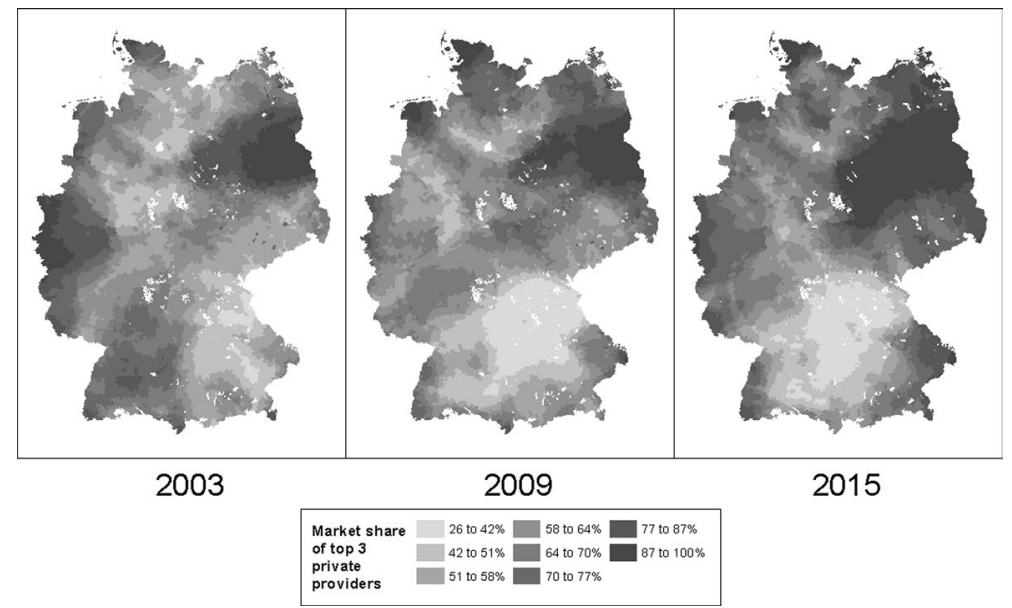

Fig. 2 Market concentration (CR3) for solid waste collection in Germany, 2003, 2009, and 2015. Source: The authors, based on the municipality dataset

independent decisions given the significant economies of scale in providing waste collection services.

\subsubsection{Results}

Table 4 shows the results for separate estimates for episode 1, episode 2, a pooled model, and a model with interaction terms (which is our preferred specification). We show the marginal effects for each variable and the standard errors of the underlying estimated coefficient in parentheses.

Continuous variables - which are not indicator variables or shares-are in logarithms. Accordingly, the depicted effects represent percentage point changes for all variables: E.g., a 1 percent increase in population results in a 1.35 percentage point increase in the switching probability in the pooled model. This is measured around the sample average, which is 13,010 residents.

Equally, an increase of the CR3 by 1 percentage point results in a 0.164 percentage point increase in the switching probability in the pooled model. Again, this is measured around the sample average, which is $62.0 \%$.

Note that the average switching probability is $8.0 \%$. The marginal effects are plausible estimates only for smaller changes: e.g., a 1 percentage point change in the explanatory variable. ${ }^{25}$

All models include state fixed effects for the 13 German Federal States without the city-states of Berlin, Hamburg, and Bremen. ${ }^{26}$ The pooled and the interacted

\footnotetext{
25 In Table 6, we show the effects of more drastic changes in the measures of local competition.

26 The two city-states of Berlin and Hamburg had public provision throughout, and Bremen had private provision throughout.
} 


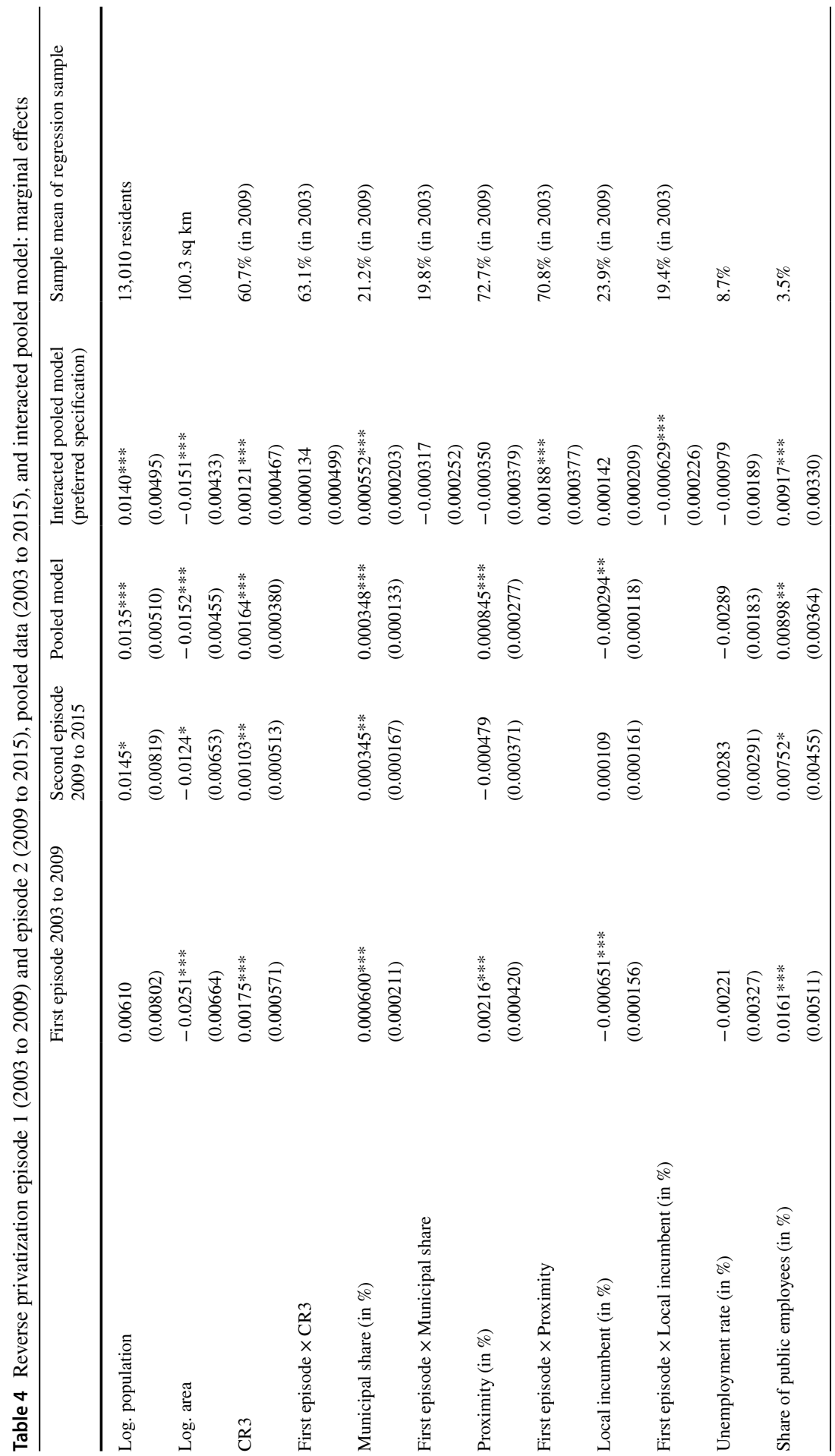




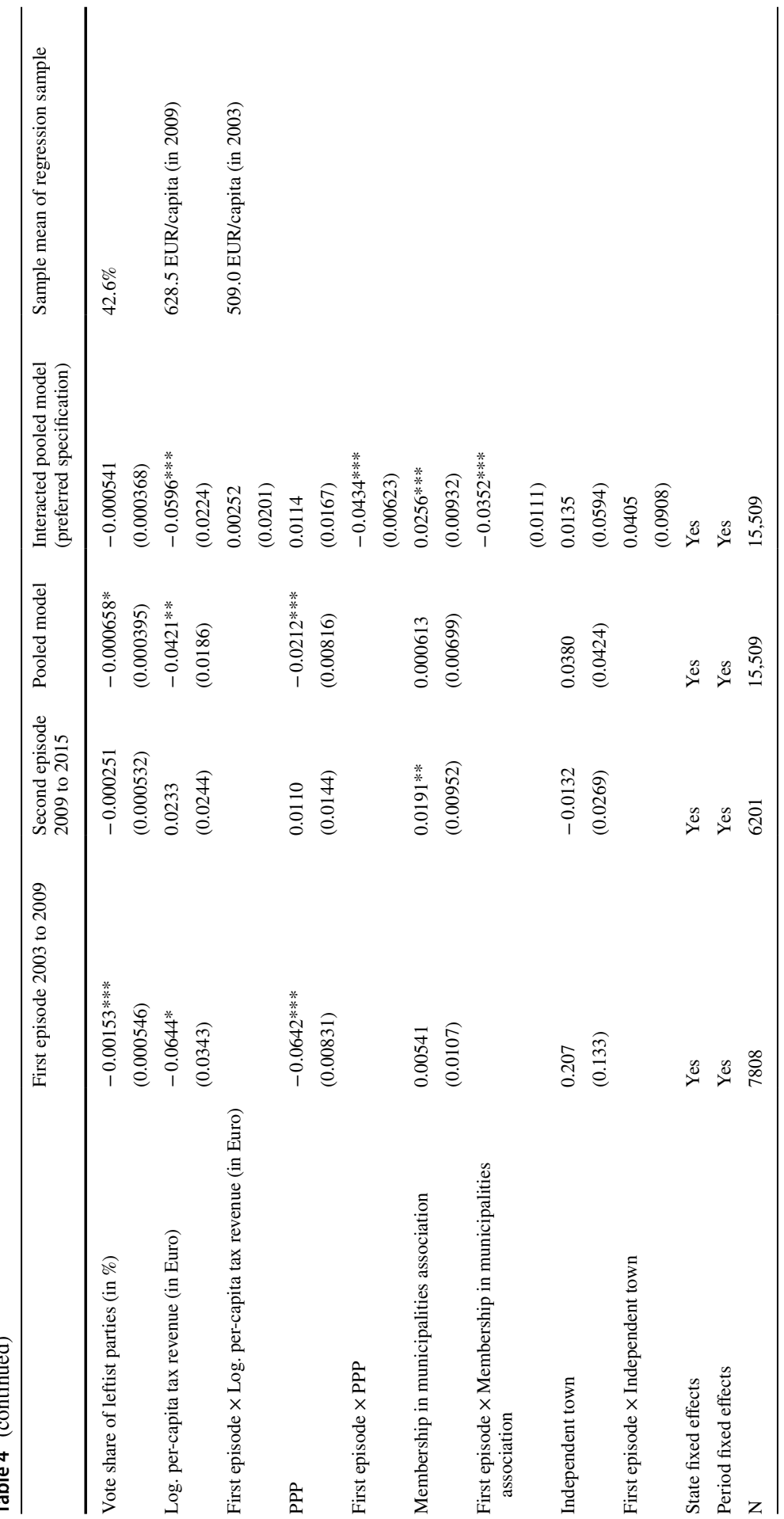




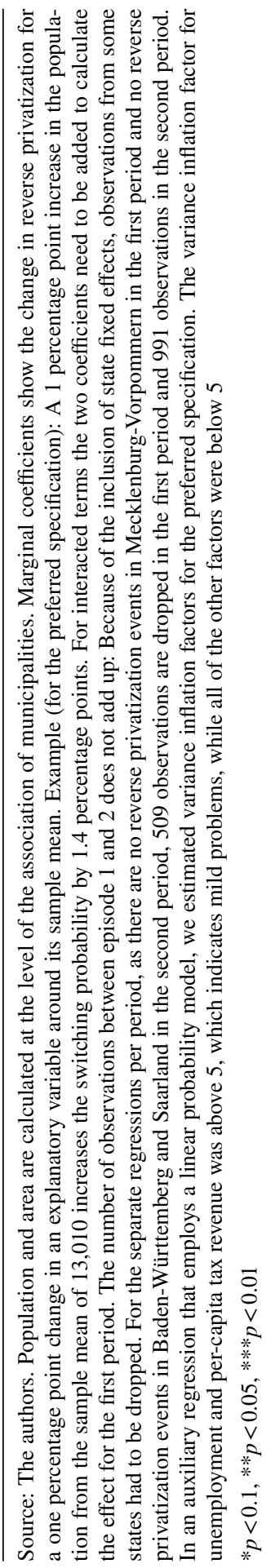


model, which cover both the first and the second episodes, also include time fixed effects for both episodes. Hence, in all models, identification comes via within-state variation and non-common time variation.

For instance, the impact of the financial crisis, to the extent that it affected all municipalities' switching probability equally, should therefore be captured by the time fixed effects. In a further sensitivity check, we also add state fixed effects interacted with the episode dummy, thereby controlling for state specific effects of the financial crisis.

Overall, we can rely on 15,509 observations, of which 8,317 are part of episode 1 and 7,192 are part of episode 2. Note that the combined number of observations in the two separate estimations is slightly lower than in the pooled and interacted estimations. This is because for separate estimations some state fixed effects could not be estimated properly and, hence, the observations for those states had to be dropped. $^{27}$

Examining the episodes separately (columns one and two) and comparing the results to the pooled model (column 3), we find across the three models consistent and statistically significant effects for the area, CR3, municipal share, and employment share of public employees variables. The coefficients of the proximity, local incumbent, vote share of leftist parties, per-capita tax revenue, and PPP variables are statistically significant only in the first episode (and in the pooled model); membership in a municipality association is significant only for the second episode. The population measure becomes statistically significant only for the pooled model.

Given the observable differences between the two episodes, we estimated a model that allows different coefficients for the variables in focus as well as for those variables for which we observed statistically significant differences in the coefficients that were estimated in the two separate regressions for each period.

More specifically: We used a dummy variable for the first episode with the variables that are related to local competition and municipal activity: CR3, municipal share, proximity, local incumbent, as well as per-capita tax revenue, PPP, membership in the municipal association, and the independent town dummy variable. This model is labeled the interacted pooled model and is our preferred specification. ${ }^{28}$

To further explore the stability of the preferred specification and, in particular, the estimated coefficients related to the local competition, we estimated the model with a reduced set of variables (see Table 5).

\footnotetext{
27 The states for which observations are dropped in the separate regressions are those states for which we do not observe any switches during a period (one state in the first period and two states in the second period). We estimated the pooled and the interacted model also on the restricted observations of the separated estimations. The results hold up to this variation.

28 In "Appendix 2", we offer further sensitivities to this question. In particular we allow for episodespecific state fixed effects and include interaction terms for the policy variables as well. We find that the population-related effect becomes insignificant when interacted state fixed effects are added. The fiscal stress variable - per capita tax revenue-is in the fully interacted model statistically significant only in the first episode. All effects that are related to local competition remain statically significant and increase slightly in size. As we lose around $10 \%$ of the observations by adding interacted state fixed effects and given the stability of the core variables, we consider the pooled interacted specification to be superior.
} 


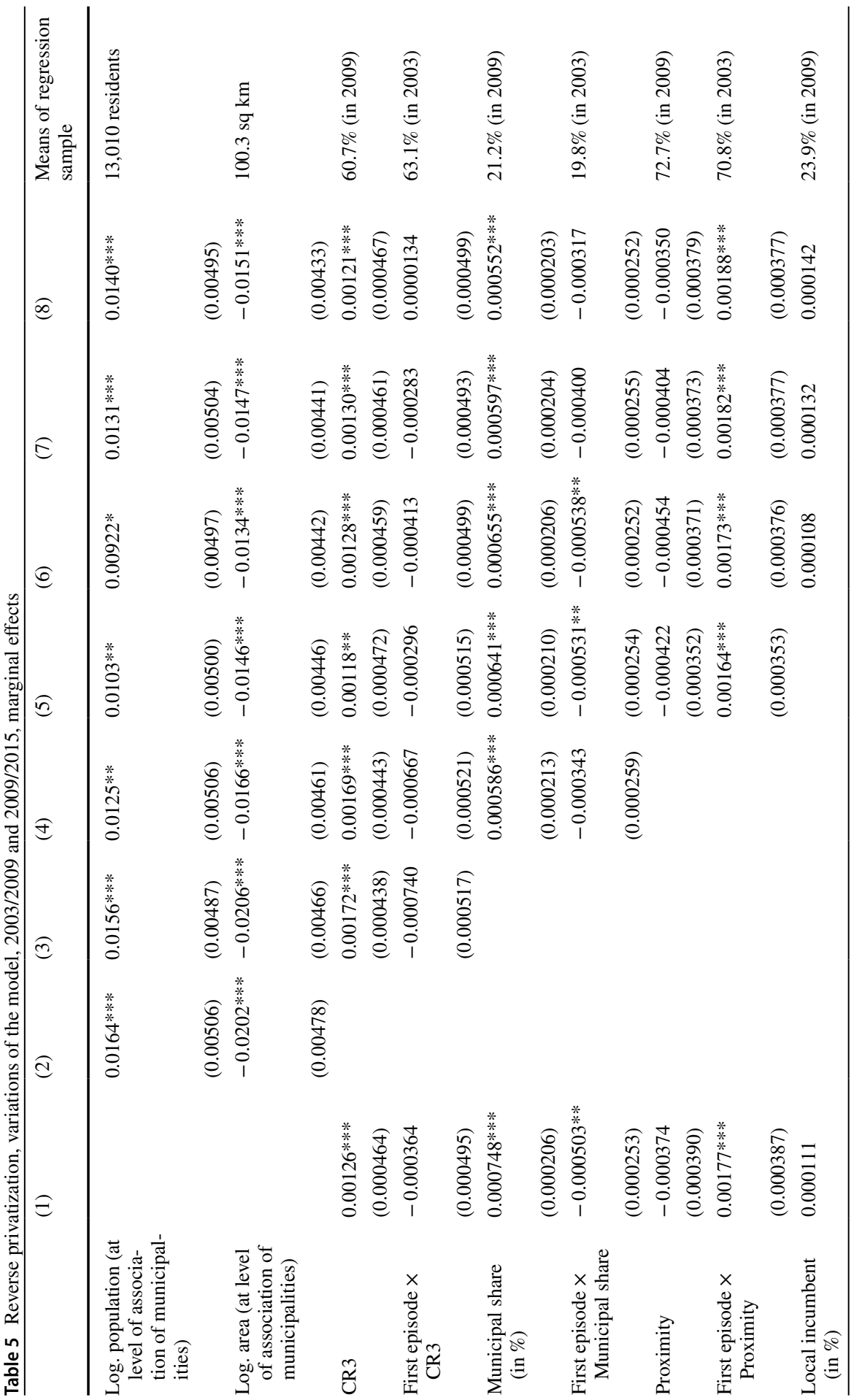




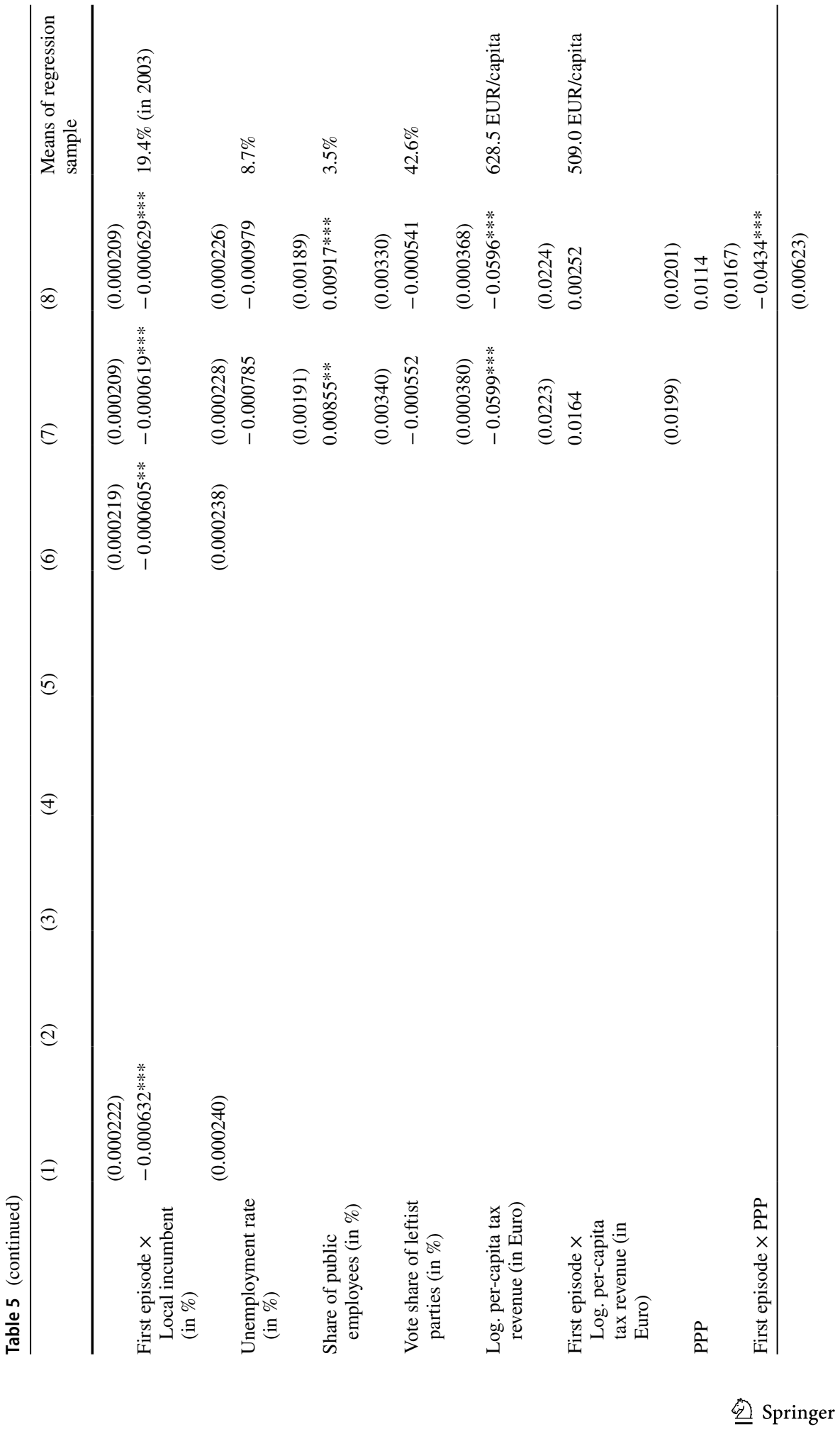




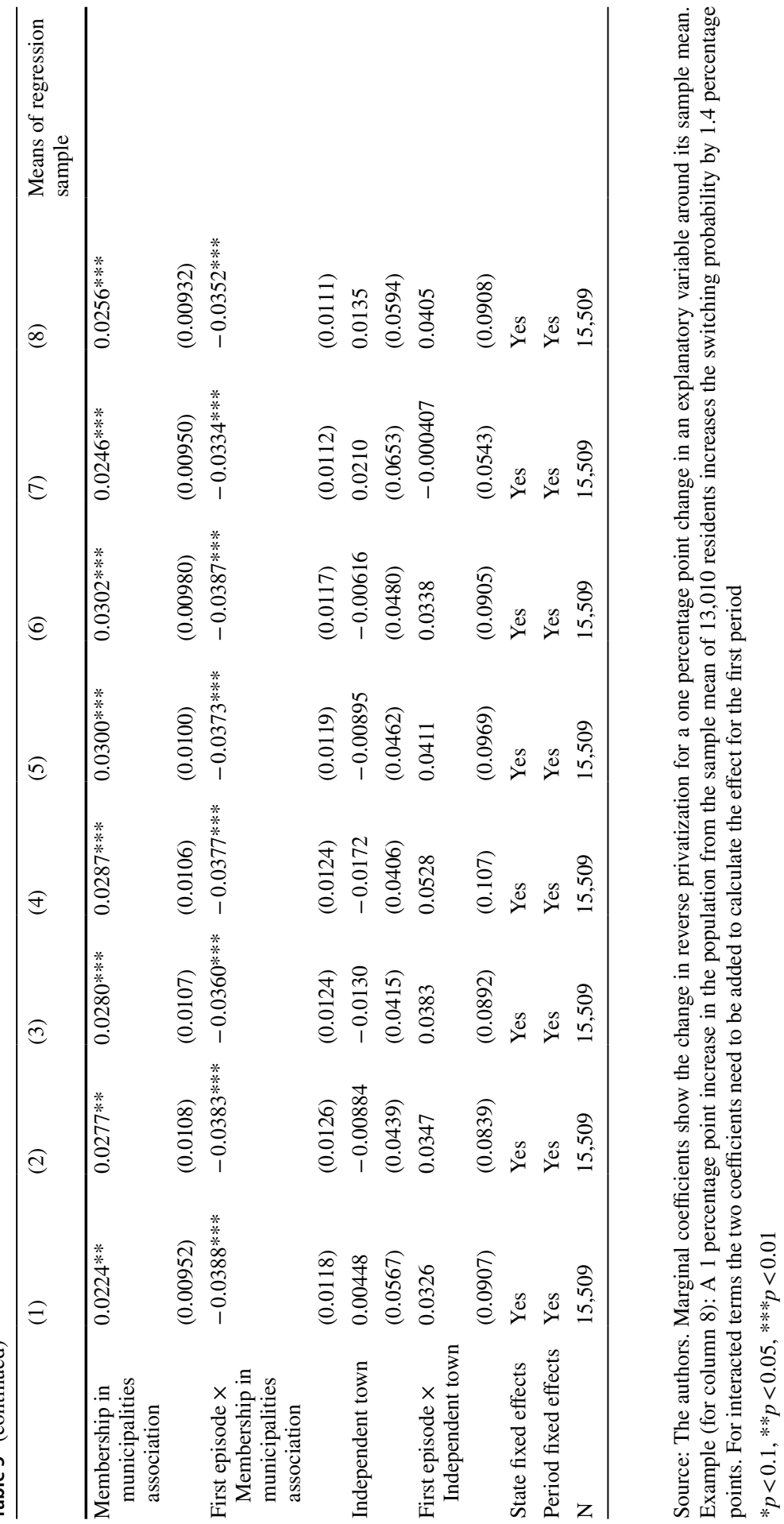


In the first variant, we include the local competition and municipal activity variables in isolation. In the following columns, we build up the model starting with those explanatory variables for which the literature has identified robust relationships: population/efficiency-related measures. In variants 3 to 6 , we include the factors that are of central interest to this paper: variables that are related to local competition and close-by public activity. Political variables and fiscal constraints-related variables are included in variant 7; and, in addition, the indicator variable for public-private partnerships is included in variant 8. State and episode fixed effects are included in all specifications; the estimations are run over the same sample.

We offer the following observations: First, without further controls, we find that reverse privatization is more likely when: i) the concentration among private suppliers is high; ii) other close-by municipalities have in-house provision; iii) a public waste incinerator is close; and iv) no (private) local incumbent holds the contract. These results are robust when other control variables are included. In particular, the concentration measure-CR3 - is statistically significant in both episodes.

However, we also see indications that proximity to waste incinerators and the existence of a local incumbent is more important in the first episode of reverse privatization, while the share of municipalities in some specifications is more important in the second episode.

These results are consistent with the results reported in Bel and Fageda (2017), who report that privatization is more likely with a higher number of competitors available. Conversely, with higher concentration reverse privatization becomes likely. Additionally, there is evidence for spatial dependency in the privatization decision, which we also see in the positive relationship between reverse privatization and the municipal share of public provision.

Such spatial dependency has also been found to be important by Alonso et al. (2016) for the outsourcing decision of English local governments with respect to leisure services and by Picazo-Tadeo et al. (2012) for the privatization decision of water services by 741 municipalities in the south of Spain.

Second, the local population has a positive influence on reverse privatization, while the area has a negative influence. Taken together, this suggests that reverse privatization is more likely in densely populated areas. For the second episode, we also find in the above regressions that membership in a municipal association induces a higher probability to reverse privatization; this hints again as to the importance of the size of a municipality (or here a group of municipalities) for reverse privatization. This confirms the "static" result by Böckers et al. (2017), who found that public provision is more likely in more extensive and more densely populated areas in Germany.

Third, the coefficient on tax revenue per capita, which is an (inverse) measure of fiscal constraints, exhibits a negative coefficient: Greater tax revenue implies a reduced probability of reverse privatization. With regard to per capita tax revenue, Bel and Fageda (2017) have generally found a positive relationship between fiscal stress and privatization.

Nonetheless, our results indicate that higher per capita tax revenue leads to less reverse privatization; conversely, fiscal stress has a positive relationship with reverse privatization. One potential explanation for this result is that switching in either 
direction becomes more likely in situations of fiscal stress. Another explanation could lie in the focus of earlier studies in the US: As Bel and Fageda (2017, p. 505) point out, the few studies that have been conducted in European countries find the same relationship as we find in our data.

Consequently, reverse privatization may be seen as a manifestation of the 'politics of bad times', where bringing a profitable service under the control of the municipality may be seen as a valid strategy from a budgetary perspective. This motive is often the driver for reverse privatization in Germany but does not always materialize ex post (German Competition Authority, 2014, S.18). This can be rationalized because municipalities that provide services in-house can cross-subsidize less profitable services, such as cleaning public parks, without having to explicitly raise taxes.

Fourth, with respect to the measures of political processes-the unemployment rate, and the employment share of public employees-we find some effects; whereas for ideological attitudes - the vote share of leftist parties-we do not find statistically significant effects. ${ }^{29}$

While this is in line with the studies that have been conducted in the US, several studies that have been conducted in Europe find some ideological bias (see the literature that is cited in Bel Fageda, 2017, p. 508). This may indicate that ideological motives are less important for solid waste collection, a mere technical service-as opposed to other social services; this is a distinction that is also noted in Bel and Fageda (2017) and confirmed by Elinder and Jordahl (2013) in a study in Sweden.

\subsubsection{The Economic Effects of Local Competition}

To assess whether the explanatory variables for local competition and municipal activity have an economically significant effect, we simulated how the predicted probability varies at different percentiles in the distribution of those variables, either in isolation or taken together. Table 6 shows this exercise, based on the model in column 8 of Table 5 .

The results show that variations in concentration and proximity are capable of moving predicted probabilities of switching by considerable amounts compared to the median probability of around $12.1 \%$ in the first period and $4.6 \%$ in the second period. For instance, moving from the 25 th percentile to the 75 th percentile in the observed distribution of the CR3 results in a change in switching probability of 2.7 percentage points in episode 1 and 1.7 percentage points in episode 2 .

Overall, the variables that capture local competition and municipal activity in vertically and horizontally related markets are capable of inducing changes in switching probabilities from 0.6 to $36.5 \%$ in the first episode and from 3.8 to $14.9 \%$ in episode 2. The effects, due to the interaction term, are not always statistically significant for both episodes. Excluding statistically insignificant effects does not, however, change the results qualitatively. ${ }^{30}$

\footnotetext{
${ }^{29}$ Ideological attitudes may be more persistent and may therefore be captured by state fixed effects.

30 If we focus only on significant effects, overall, the variables that capture local competition and municipal activity in vertically and horizontally related markets are capable of inducing changes in switching probabilities from 0.7 to $31.4 \%$ in the first period (significant coefficients for CR3, proximity and local
} 


\subsubsection{Robustness Checks of the Model}

Several robustness checks have been carried out: First, we checked the robustness of our results with respect to the measure of market concentration-CR3 versus $\mathrm{HHI}-$ and the radius that we used for the calculation of local concentration: $100 \mathrm{~km}$ versus $50 \mathrm{~km}$ versus $25 \mathrm{~km}$.

As can be seen in Table 7, the marginal effect that is related to CR3 is positive and significant for both periods when calculated based on a $100 \mathrm{~km}$ radius (first and second column). When the radius is reduced to $50 \mathrm{~km}$ or even $25 \mathrm{~km}$, the coefficient becomes statistically not significant and is diminished (third and fourth column).

Using the HHI instead of the CR3 as an indicator, which also incorporates changes in concentration among the smaller market players, we find again a positive and statistically significant effect (fifth column). Those results are in line with the practice of the German Competition Authority to delineate relevant geographic markets with a $100 \mathrm{~km}$ radius around a municipality. ${ }^{31}$

A second robustness check explores the effect of using the election data of municipal elections instead of the results of national elections on a municipal level to determine the vote share of leftist parties (in "Appendix 3"). ${ }^{32}$ As decisions about the mode of service provision for solid waste collection are taken at the municipal level, in principle results of municipal elections would be better suited as an explanatory variable for reverse privatization of solid waste collection services.

For this purpose, we compiled a dataset that is based on the municipal election data that are provided by the individual statistical offices of each of the German states. Again, the results for all other variables remain robust (with some indications that the effect of changes of the municipal share in the first period is lower than in the second episode). The marginal effect of the vote share of leftist parties-which is negative and statistically insignificant in our preferred specification-becomes in this specification positive (as one would intuitively expect) but still insignificant.

\footnotetext{
Footnote 30 (continued)

incumbent) and from 2.3 to $17.9 \%$ in the second period (significant coefficients for CR3 and municipal share).

${ }^{31}$ To some extent, they are potentially also driven though by the issue that-when measured at the same geographic market- the municipal share and the concentration measure interact with each other and the effects cannot be properly separated. In Table 11 in the "Appendix 3", we show a further robustness check with respect to the radius of the municipal share. Also there we observe that when measured for the same radius $(100 \mathrm{~km})$ the effects of the concentration measure and the municipal share cannot be separated.

${ }^{32}$ In "Appendix 3", we also replaced the population and area at the association level with the respective measures at the individual municipalities' level (third data column of Table 11) and included municipalities with 251 to 500 residents (fourth data column of Table 11). Both variants do not change the estimated marginal effects in a qualitatively substantial way compared to our preferred specification. Furthermore, we also conducted a robustness check, where the population-weighted CR3 measures are replaced by a municipality-count based measure of CR3: showing the frequency of the three suppliers with the largest count among municipalities in a $100 \mathrm{~km}$ radius around the target municipality. The coefficient for the municipality-count based measure differs between the first and second waves. However, both coefficients are not statistically different (at the 5\% level) from the baseline effect in the preferred specification with the population-weighted CR3 measure.
} 
Table 6 Predicted probabilities of reverse privatization at different percentiles of the distribution of local competition and municipal variables

\begin{tabular}{|c|c|c|c|c|c|c|c|}
\hline Percentile & $1 \%$ & $10 \%$ & $25 \%$ & $50 \%$ & $75 \%$ & $90 \%$ & $99 \%$ \\
\hline \multicolumn{8}{|l|}{ Episode 1} \\
\hline CR3 & 6.4 & 7.7 & 8.6 & 9.7 & 11.3 & 12.9 & 16.9 \\
\hline Municipal share & 9.1 & 9.1 & 9.1 & 9.6 & 10.4 & 11.0 & 12.3 \\
\hline Proximity & 2.5 & 5.0 & 8.2 & 11.7 & 14.8 & 16.7 & 18.7 \\
\hline Local incumbent ${ }^{\mathrm{a}}$ & 4.9 & 4.9 & 9.8 & 11.0 & 11.1 & 11.1 & 11.2 \\
\hline Variation in & 0.6 & 1.6 & 6.4 & 12.1 & 18.8 & 24.9 & 36.5 \\
\hline \multicolumn{8}{|l|}{ Episode 2} \\
\hline CR3 & 3.0 & 3.7 & 4.7 & 5.6 & 6.4 & 7.6 & 11.4 \\
\hline Municipal share & 4.6 & 4.6 & 4.6 & 5.4 & 6.6 & 7.6 & 9.6 \\
\hline Proximity & 7.9 & 6.8 & 6.0 & 5.5 & 5.2 & 5.1 & 4.9 \\
\hline Local incumbent ${ }^{\mathrm{a}}$ & 7.1 & 7.1 & 6.1 & 5.7 & 5.7 & 5.7 & 5.7 \\
\hline Variation in all & 3.8 & 4.0 & 3.8 & 4.6 & 6.0 & 8.2 & 14.9 \\
\hline
\end{tabular}

Source: The authors

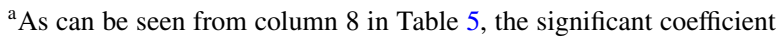
of the local incumbent in the first episode is negative. We vary the percentiles for local incumbent in reverse order: $100 \%$ minus the percentile. The median values of the distribution of the local competition and municipal activity variables are for the first episode: CR3 61.8\%; municipal share $14.5 \%$; proximity $75.5 \%$; and local incumbent $2.3 \%$. For the second episode the median values are: CR3 $61.2 \%$; municipal share $15.8 \%$; proximity $77.8 \%$; and local incumbent $4.6 \%$

Given the limitations of this dataset that are related to the completeness and to the assignment of party/independent candidates to the political left-right-spectrum, we consider the vote share of the leftist parties that is based on national elections - as we used in our preferred specification-more reliable.

The third sensitivity to our preferred specification is depicted in Table 8. This sensitivity is based on the expected year of switchover. Ideally, one would like to identify the exact year of switching for the analysis. This is, however, not available in the dataset.

However, for a subsample of the dataset- $82 \%$ of the relevant observationsthe expected contract termination year is available. In the specification in Table 8 , column 3, we offer an estimation that uses the expected contract end as the switchover date, in the event of switching. For this purpose, we linearly interpolate the explanatory variables between the actual years of observation-2003, 2009, and 2015-to create an annual dataset of our explanatory variables. We applied a one-year lag for the explanatory variables relative to the estimated year of switching.

Comparing the different variants, we find-but for some changes due to the reduced sample-our original specification confirmed. Given the reduced sample and a potential measurement error for contracts with prolonged validity, we consider the approach that we take in our preferred specification to be more reliable. 


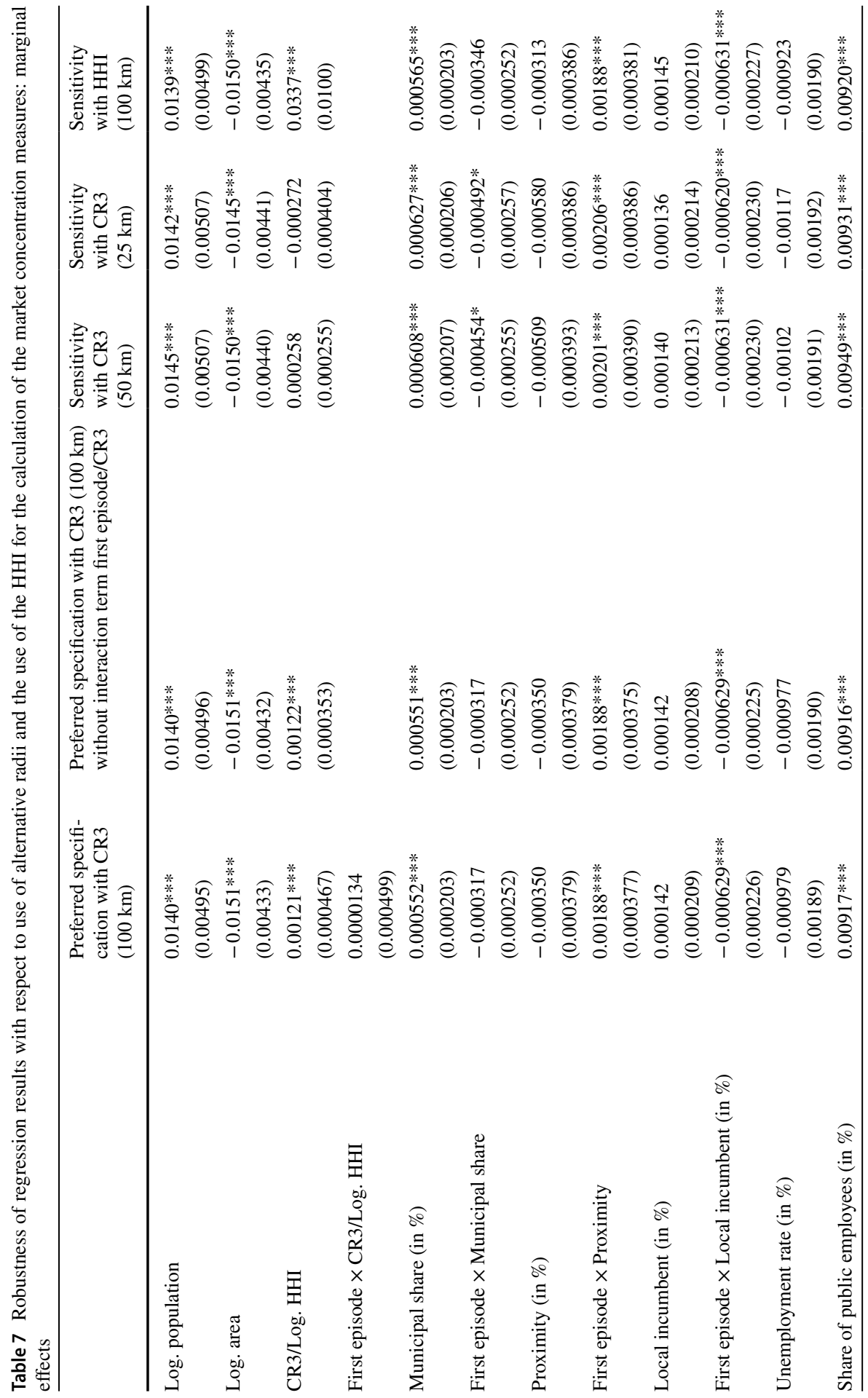




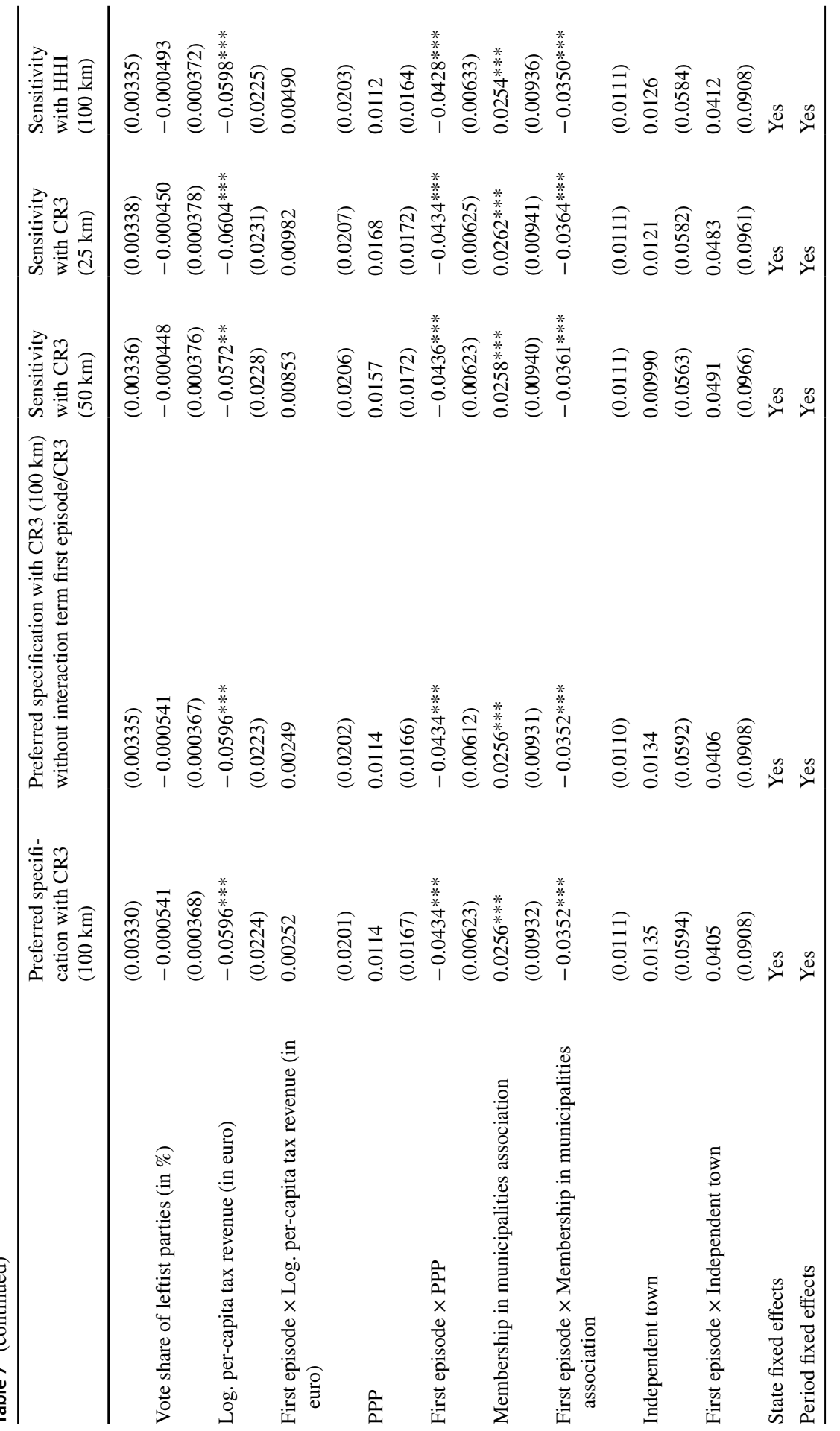




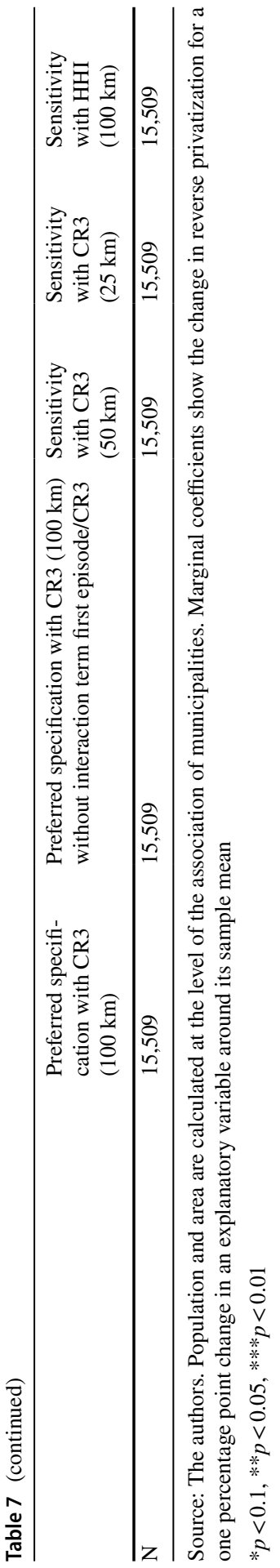




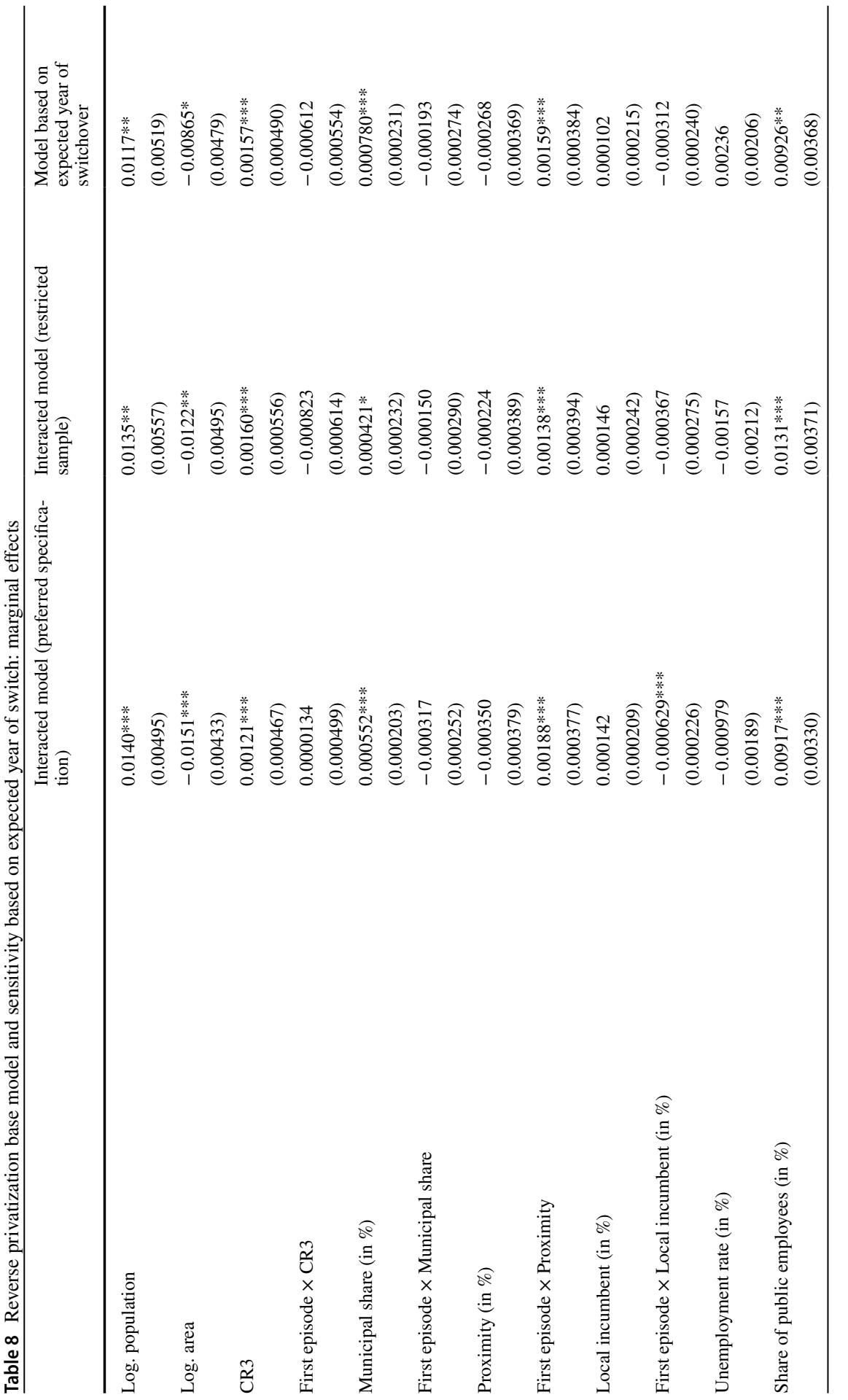




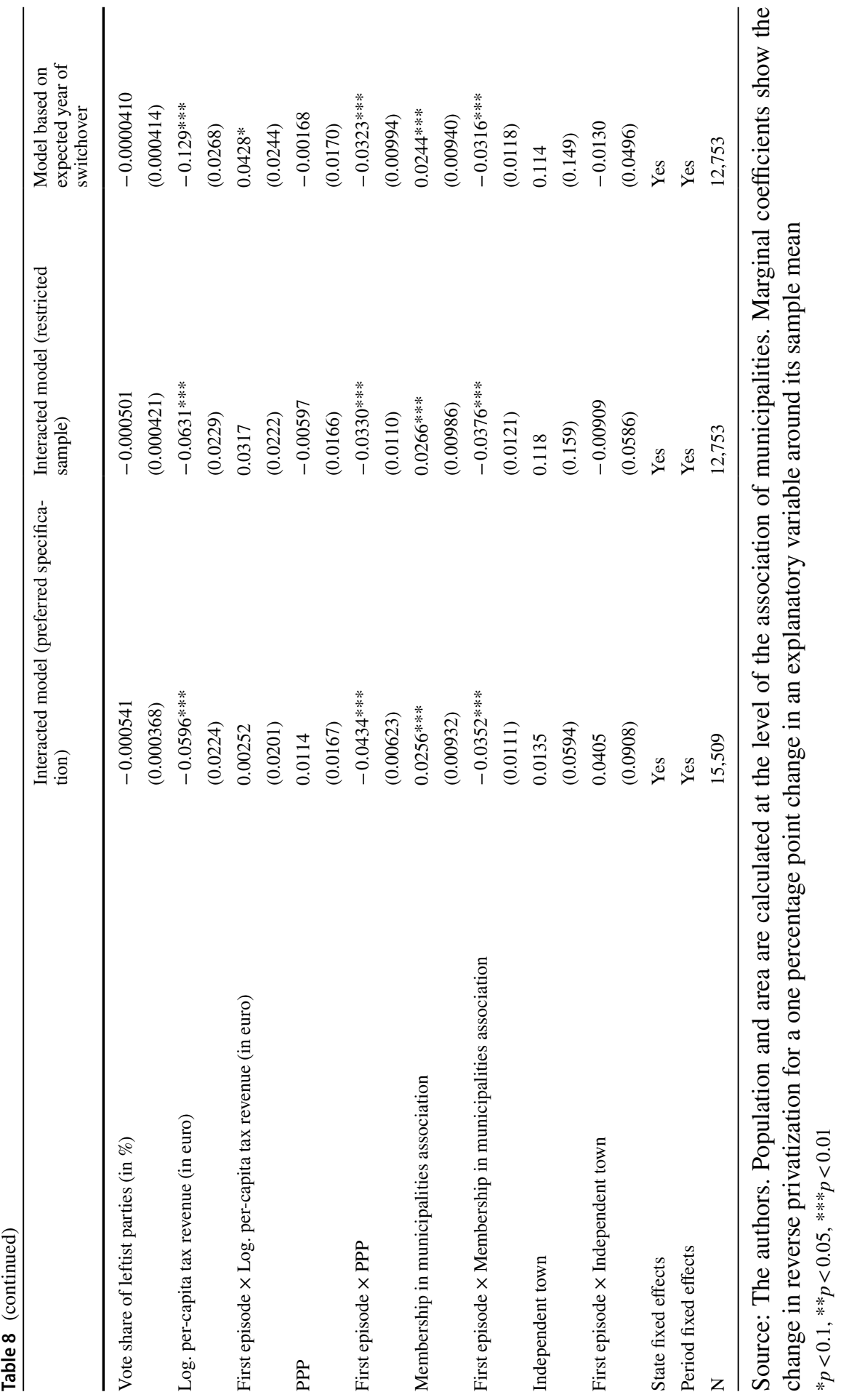




\section{Conclusion}

In this paper, we assess the evidence and the explore factors that have influenced the process of reverse privatization in the German solid waste collection sector over the years 2003 to 2015 . We show that this trend towards reverse privatization-which has been seen before in North America, New Zealand, and some European Countries-also exists for Germany.

With regard to the motives of reverse privatization, we find that measures of local competition and municipal activity play an important role in this industry.

First, our measure of local competition-the local market shares of the top three private service providers ${ }^{33}$-indicates that reverse privatization is, at least to some extent, a strategic response to weaker competition and non-competitive offerings. This result points towards a view of municipalities as active market players that restrain the market behavior of private firms. Specifically, in the second episode-2009-2015 - and in Eastern Germany, concentration increased substantially, which explains part of the trend towards reverse privatization.

Second, horizontally or vertically related public activity encourages reverse privatization. Again, this indicates some rational, profit-oriented behavior of the public provider. Horizontal coincidences are consistent with local knowledge spillovers and/or the local availability of cost-efficient public provision. ${ }^{34}$ Vertical expansion is in line with a strategic response to overcapacity in the downstream market and with an effort of the municipality to secure access to an important input product. Equally, expansion towards densely populated regions highlights a cost-oriented approach.

Finally, we find evidence that incumbents with a more local focus reduce the probability of reverse privatization. This can be due to efficient, region-centered services that are offered by these more local players; it could also be due to their political influence on local decision-making. Equally, the impact of the share of public employees to induce reverse privatization does not allow us to exclude political processes to influence this decision as well.

\footnotetext{
33 While some papers did analyze the impact of competition on the decision to privatize, none of those used the variation of local market shares to identify its relevance on reverse privatization. Other papers use responses from management surveys (such as Warner and Hefetz, 2012), the use of competitive tender procedures (Mohr et al., 2010), or the number of bidders in tender procedures (Fernandez et al., 2008); the last is information that is often not publicly available. Gradus et al. (2016) and Gradus et al. (2018) also analyze the impact of local market shares (for the Dutch market) and find that local shares affect the costs of service provision. However, these studies do not investigate the decision to privatize or not.

${ }^{34}$ Spatial dependency has also been found to be important in the UK solid waste collection market by Bivand and Szymanski (2000) and in the Spanish solid waste collection market with respect to privatization (Bel and Miralles (2003) and Bel et al. (2013)). Regional interdependence has also been shown for the outsourcing decision for other public services. Alonso, Andrews, and Hodgkinson (2016) showed its importance for the outsourcing decision of English local governments in relation to leisure services, and Picazo-Tadeo et al. (2012) show it for the privatization decision of water services by 741 municipalities in the south of Spain.
} 


\section{Appendix 1: Switching Events, Absolute Numbers}

See Table 9.

Table 9 Number of switching events, 2003/2009 and 2009/2015

\begin{tabular}{lll}
\hline & No in-house provision in 2009 & In-house provision in 2009 \\
\hline No in-house provision in 2003 & 7496 & 823 reverse privatizations \\
In-house provision in 2003 & 126 privatizations & 1150 \\
& No in-house provision in 2015 & In-house provision in 2015 \\
No in-house provision in 2009 & 6769 & 425 reverse privatizations \\
In-house provision in 2009 & 5 privatizations & 1784
\end{tabular}

Source: The authors based on the municipal dataset

\section{Appendix 2: Robustness of Regression Results with Respect to the Use of Interacted State Fixed Effects and Additional Interacted Variables}

See Table 10. 


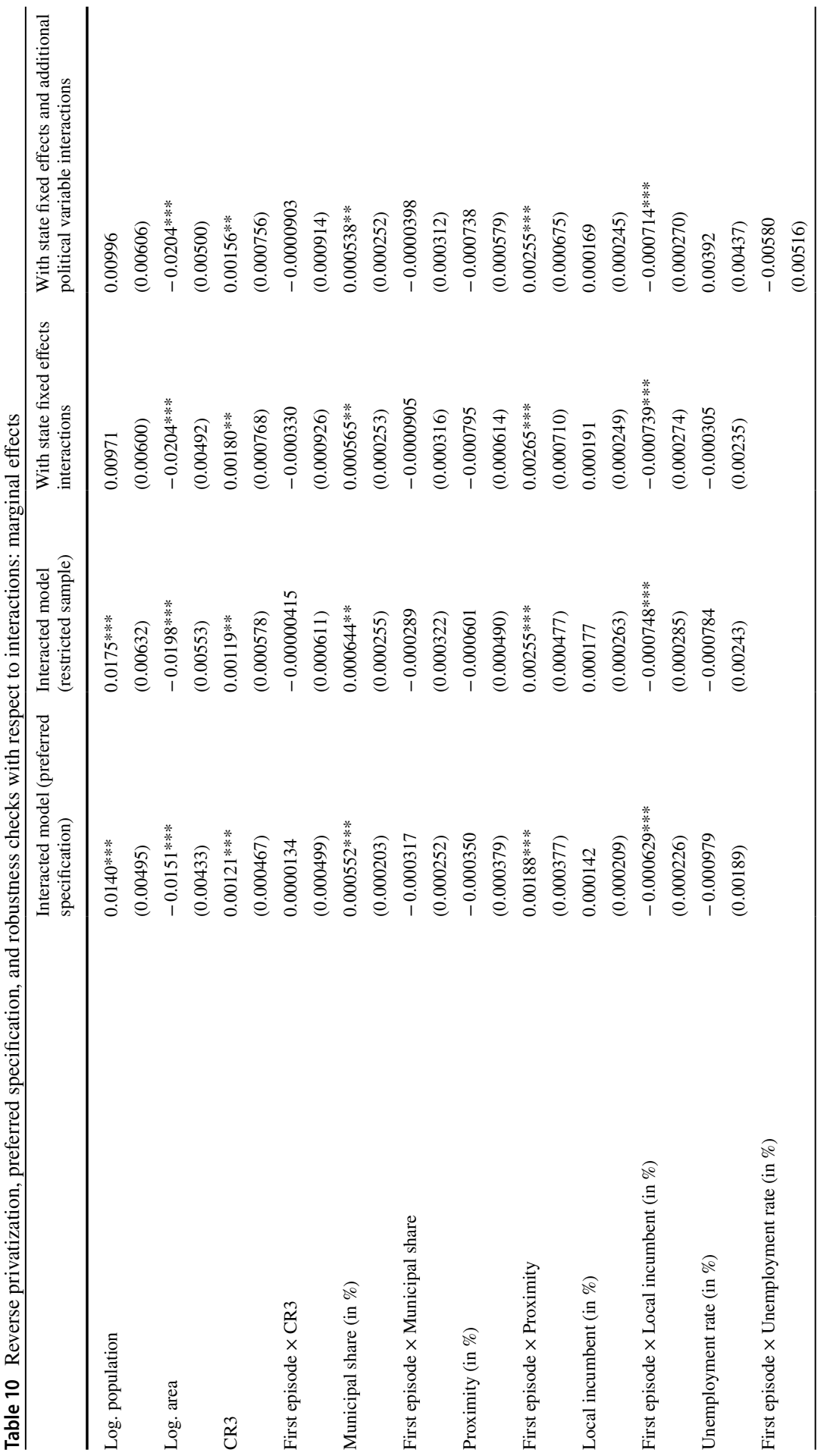




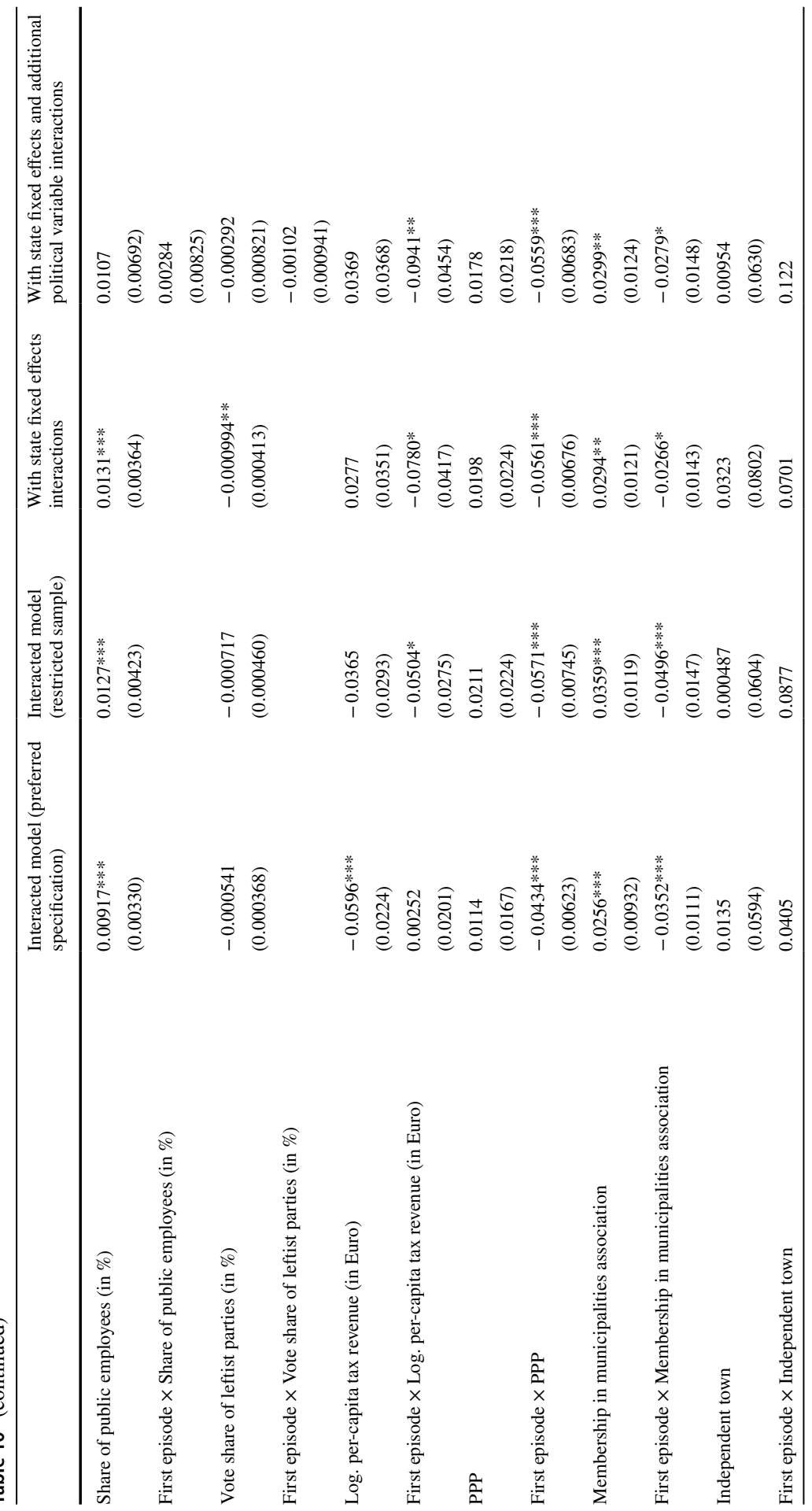




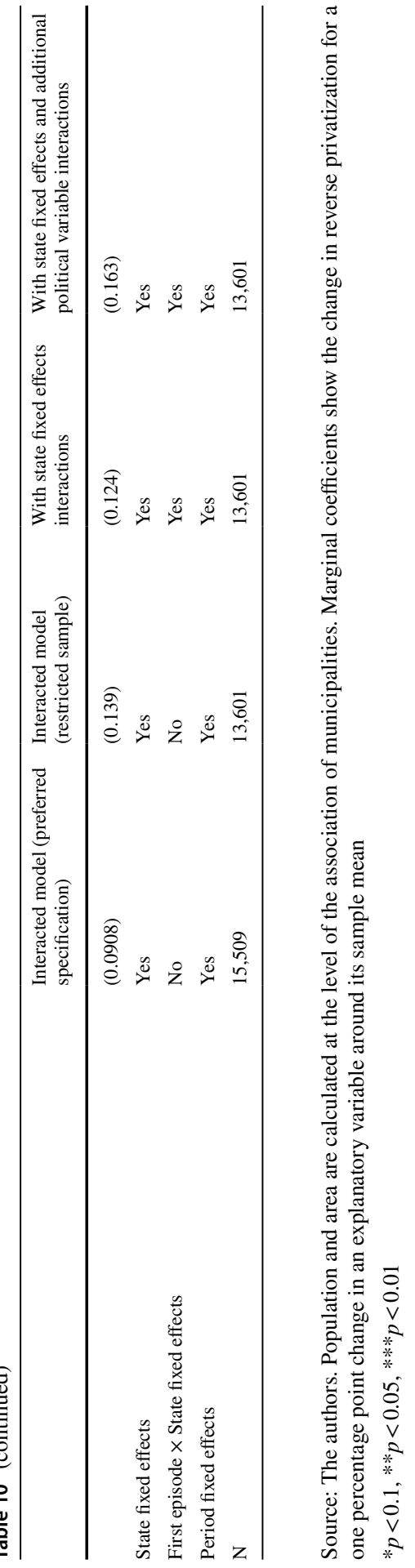




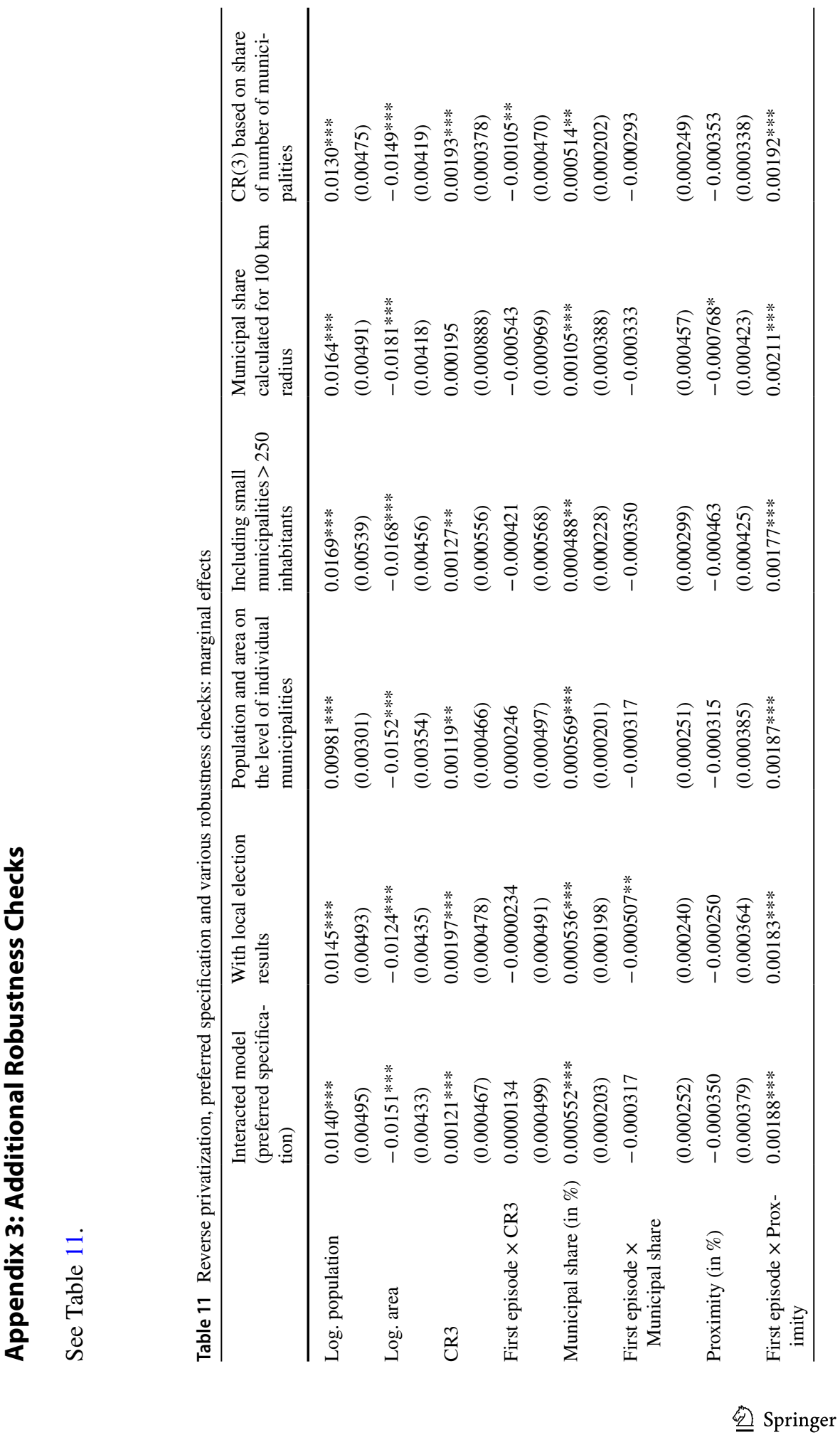




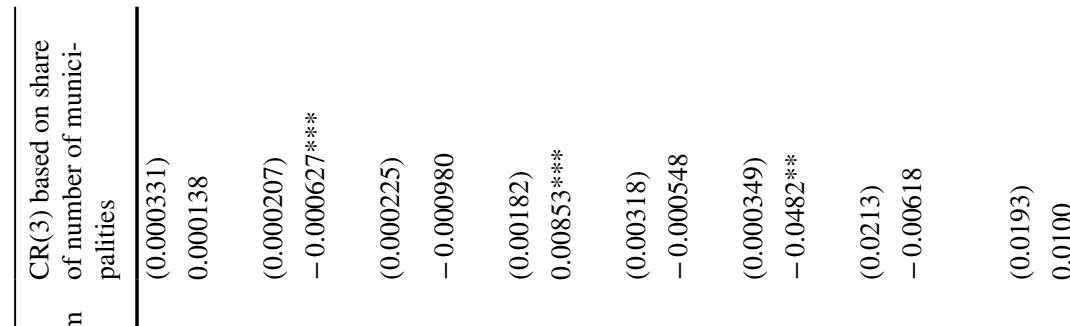

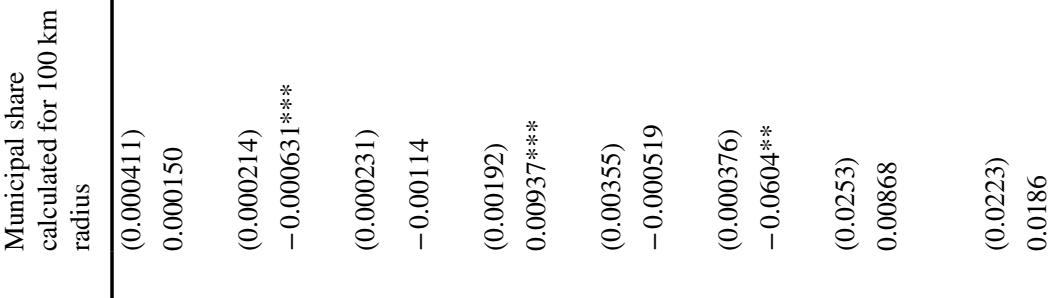

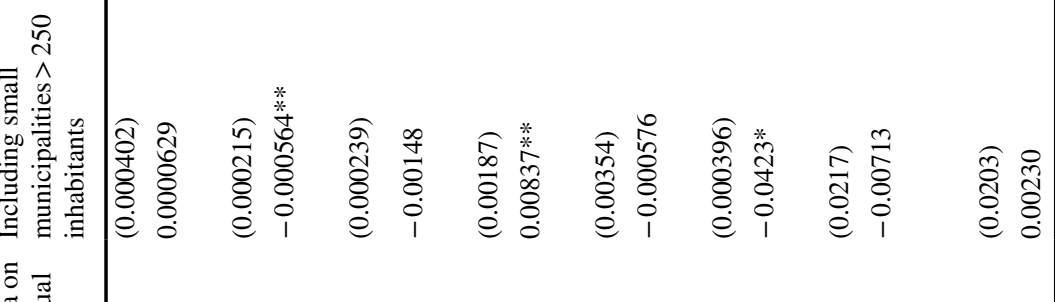

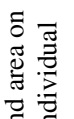

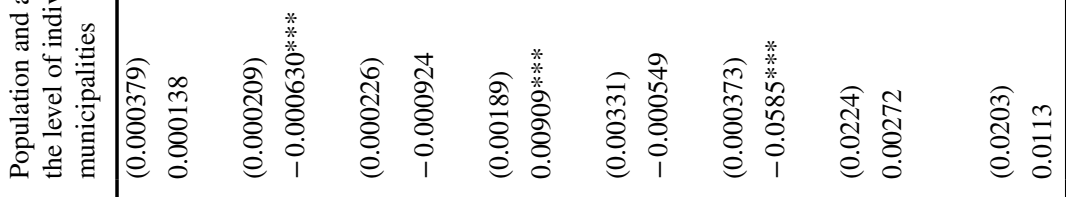

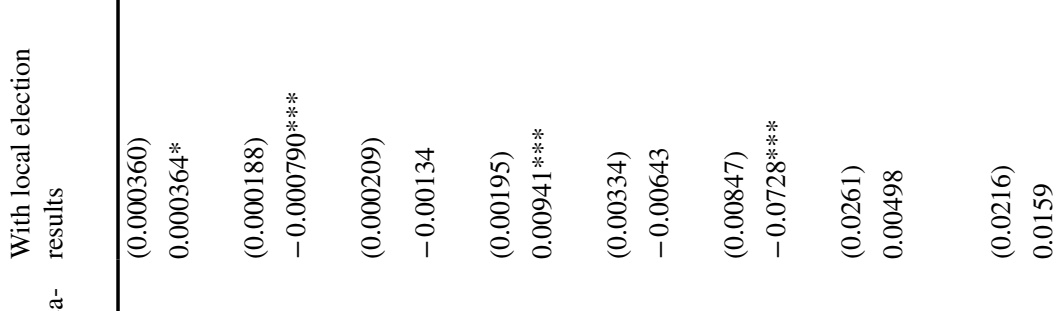

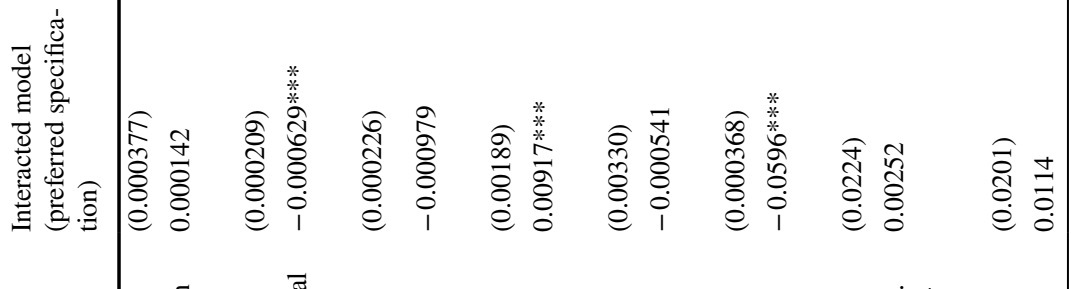

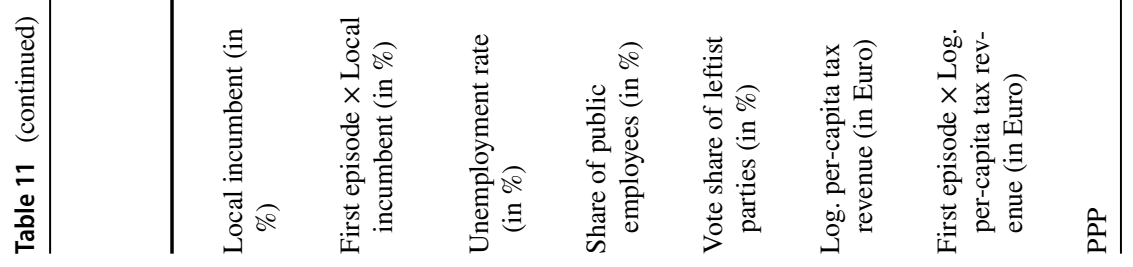




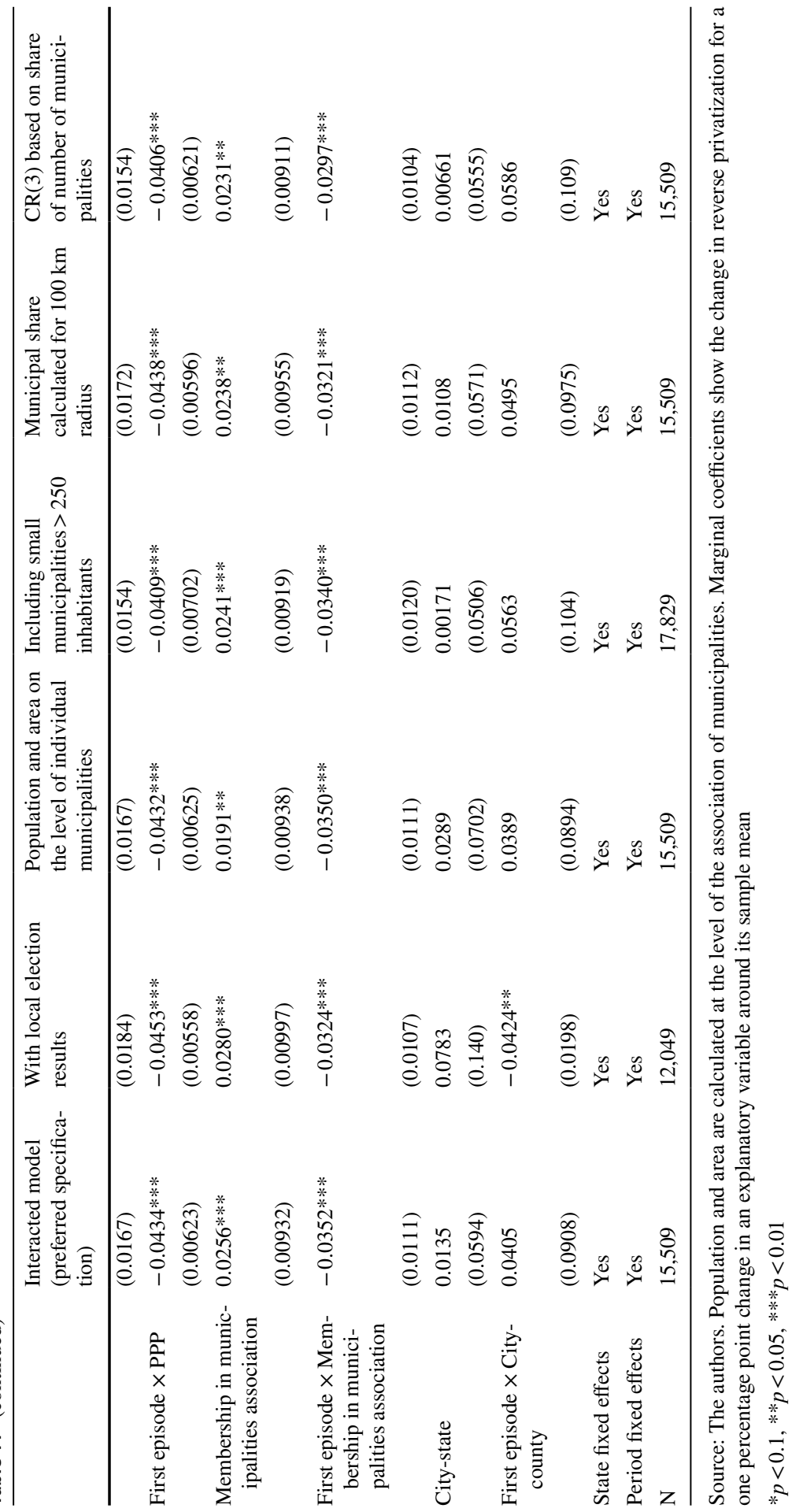


Funding Open Access funding enabled and organized by Projekt DEAL.

Open Access This article is licensed under a Creative Commons Attribution 4.0 International License, which permits use, sharing, adaptation, distribution and reproduction in any medium or format, as long as you give appropriate credit to the original author(s) and the source, provide a link to the Creative Commons licence, and indicate if changes were made. The images or other third party material in this article are included in the article's Creative Commons licence, unless indicated otherwise in a credit line to the material. If material is not included in the article's Creative Commons licence and your intended use is not permitted by statutory regulation or exceeds the permitted use, you will need to obtain permission directly from the copyright holder. To view a copy of this licence, visit http://creativecommons.org/ licenses/by/4.0/.

\section{References}

Alonso, J. M., Andrews, R., \& Hodgkinson, I. R. (2016). Institutional, ideological and political influences on local government contracting: Evidence from England. Public Administration, 94(1), 244-262.

Bel, G., \& Fageda, X. (2007). Why do local governments privatise public services? A survey of empirical studies. Local Government Studies, 33(4), 517-534.

Bel, G., \& Fageda, X. (2008). Reforming the local public sector: Economics and politics in privatization of water and solid waste. Journal of Economic Policy Reform, 11(1), 45-65.

Bel, G., \& Fageda, X. (2009). Factors explaining local privatization: A meta-regression analysis. Public Choice, 139(1/2), 105-119.

Bel, G., \& Fageda, X. (2017). What have we learned from the last three decades of empirical studies on factors driving local privatization? Local Government Studies, 43(4), 503-511.

Bel, G., Fageda, X., \& Mur, M. (2013). Why do municipalities cooperate to provide local public services? An Empirical Analysis. Local Government Studies, 39(3), 435-454.

Bel, G., \& Gradus, R. (2018). Privatisation, contracting-out and inter-municipal cooperation: New developments in local public service delivery. Local Government Studies, 44(1), 11-21.

Bel, G., \& Miralles, A. (2003). Factors influencing the privatisation of urban solid waste collection in Spain. Urban Studies, 40(7), 1323-1334.

Bergholz, C. (2018). Inter-municipal cooperation in the case of spillovers: Evidence from Western German municipalities. Local Government Studies, 44(1), 22-43.

Bergholz, C., \& Bischoff, I. (2018). Local council members' view on intermunicipal cooperation: Does office-related self-interest matter? Regional Studies, 52(12), 1624-1635.

Bivand, R., \& Szymanski, S. (2000). Modelling the spatial impact of the introduction of Compulsory Competitive Tendering. Regional Science and Urban Economics, 30, 203-219.

Blaeschke, F., \& Haug, P. (2018). Does intermunicipal cooperation increase efficiency? A conditional metafrontier approach for the Hessian wastewater sector. Local Government Studies, 44(1), 151-171.

Böckers, V., Hardorp, L., Haucap, J., Heimeshoff, U., Gösser, N., \& Thorwarth, S. (2017). Wettbewerb in der Restmüllerfassung: Eine empirische Analyse der Anbieterstruktur. List Forum Für WirtschaftsUnd Finanzpolitik, 42, 423-440.

Campos-Alba, C. M., De La Higuera Molina, E. J., Pérez-López, G., \& Zafra-Gómez, J. L. (2021). Drivers of contracting back in local governments: Analysing efficiency, opportunistic political cycles, political corruption and financial factors. Journal of Economic Policy Reform, 24(3), 347-360.

Donahue, J. D. (1989). Privatization decision: Public ends, private means. Basic Books.

Elinder, M., \& Jordahl, H. (2013). Political preferences and public sector outsourcing. European Journal of Political Economy, 30, 43-57.

Energie Brainpool. (2017, February). Beitrag thermischer Abfallbehandlungsanlagen zur Energiewende. Retrieved April 23, 2018 from https://www.energybrainpool.com/fileadmin/downl oad/Studien/Studie_2017-02-09_ITAD_Beitrag-TAB-zur-Energiewende_Energy-Brainpool.pdf.

Fernandez, S., Ryu, J. E., \& Brudney, J. L. (2008). Exploring variations in contracting for services among American local governments-Do politics still matter? American Review of Public Administration, 38(4), 439-462.

German Competition Authority. (2004, November 16). Decision Rethmann Kommunale Dienste Nord $\mathrm{GmbH} /$ Entsorgungs-Service Anhalt-Mitte GmbH / Tönsmeier Entsorgungsdienste GmbH / Gesellschaft für Abfallwirtschaft Köthen mbH, B10 -74/04. Retrieved September 29, 2021 from 
https://www.bundeskartellamt.de/SharedDocs/Entscheidung/DE/Entscheidungen/Fusionskon trolle/2004/B10-74-04.html.

German Competition Authority. (2005, February 23). Decision Remondis Unternehmensbeteiligungs GmbH / Rethmann AG \& Co. KG / RWE Umwelt AG, B10-122/04. Retrieved September 29, 2021 from https:/www.bundeskartellamt.de/SharedDocs/Entscheidung/DE/Entscheidungen/ Fusionskontrolle/2005/B10-122-04.html.

German Competition Authority. (2006, April 6). Sulo GmbH / Cleanaway Deutschland Holding GmbH, B10 - 151/05. Retrieved September 29, 2021 from https://www.bundeskartellamt.de/ SharedDocs/Entscheidung/DE/Entscheidungen/Fusionskontrolle/2006/B10-151-05.html.

German Competition Authority. (2014, October). The State as entrepreneur - (re-) municipalization from a competition law point of view. Discussion paper (in German) for the meeting of the Working Group on Competition Law, Bonn 2.10.2014. Retrieved September 29, 2021 from https://www.bundeskartellamt.de/SharedDocs/Publikation/DE/Diskussions_Hintergrundpapier/ Bundeskartellamt\%20-\%20Der\%20Staat\%20als\%20Unternehmer.html?nn=3590858.

Gradus, R., \& Budding, T. (2020). Political and institutional explanations for increasing re-municipalization. Urban Affairs Review, 56(2), 538-564.

Gradus, R., Dijkgraaf, E., \& Schoute, M. (2016). Is there still collusion in the Dutch waste collection market? Local Government Studies, 42(5), 689-697.

Gradus, R., Dijkgraaf, E., \& Wassenaar, M. (2014). Understanding mixed forms of refuse collection, privatization, and its reverse in the Netherlands. International Public Management Journal, 17(3), 328-343.

Gradus, R., Schoute, M., \& Dijkgraaf, E. (2018). The effects of market concentration on costs of local public services: Empirical evidence from Dutch waste collection. Local Government Studies, 44(1), 86-104.

Hall, D., Lobina, E., \& Terhorst, P. (2013). Re-municipalisation in the early twenty-first century: Water in France and energy in Germany. International Review of Applied Economics, 27(2), $193-214$

Hefetz, A., \& Warner, M. (2004). Privatization and its reverse: Explaining the dynamics of the government contracting process. Journal of Public Administration Research and Theory, 14(2), 171-190.

Hefetz, A., \& Warner, M. (2007). Beyond the market versus planning dichotomy: Understanding privatisation and its reverse in US cities. Local Government Studies, 33(4), 555-572.

Levin, J., \& Tadelis, S. (2010). Contracting for government services: Theory and evidence from US cities. Journal of Industrial Economics, 58(3), 507-541.

Mohr, R., Deller, S. C., \& Halstead, J. M. (2010). Alternative methods of service delivery in small and rural municipalities. Public Administration Review, 70(6), 894-905.

Monopolies Commission. (2014). Municipal economic activities and the observable trend towards remunicipalisation. In Monopolies Commission (2014). A competitive order for the financial markets. Bonn. XXth Main Report of the Monopolies Commission (2012/2013; in German). Chapter 5, p. 439 to 510. Retrieved September 29, 2021 from https://www.monopolkommission.de/images/PDF/ HG/HG20/5_Kap_HG20.pdf.

Picazo-Tadeo, A. J., Gonzáles-Gómez, F., Wanden-Berghe, J. G., \& Ruiz-Villaverde, A. (2012). Do ideological and political motives really matter in the public choice of local services management? Evidence from urban water services in Spain. Public Choice, 151, 215-228. https://doi.org/10.1007/ s11127-010-9744-0

Warner, M., \& Aldag, A. (2021). Re-municipalization in the US: A pragmatic response to contracting. Journal of Economic Policy Reform, 24(3), 319-332.

Warner, M., \& Hebdon, R. (2001). Local government restructuring: Privatization and its alternatives. Journal of Policy Analysis and Management, 20(2), 315-336.

Warner, M., \& Hefetz, A. (2012). Insourcing and outsourcing. The dynamics of privatization among U.S. municipalities 2002-2007. Journal of the American Planning Association, 78(3), 313-327.

Publisher's Note Springer Nature remains neutral with regard to jurisdictional claims in published maps and institutional affiliations. 